\title{
High-Definition X-Ray Fluorescence: Applications
}

\author{
Walter M. Gibson, Z. W. Chen, and Danhong Li \\ X-Ray Optical Systems, Inc. 15 Tech Valley Drive, East Greenbush, NY 12061, USA \\ Correspondence should be addressed to Walter M. Gibson, wgibson@xos.com
}

Received 5 March 2008; Accepted 14 July 2008

Recommended by Ladislav Pina

Energy dispersive X-ray fluorescence (EDXRF) is a well-established and powerful tool for nondestructive elemental analysis of virtually any material. It is widely used for environmental, industrial, pharmaceutical, forensic, and scientific research applications to measure the concentration of elemental constituents or contaminants. The fluorescing atoms can be excited by energetic electrons, ions, or photons. A particular EDXRF method, monochromatic microbeam X-ray fluorescence (M $\mu$ EDXRF), has proven to be remarkably powerful in measurement of trace element concentrations and distributions in a large variety of important medical, environmental, and industrial applications. When used with state-of-the-art doubly curved crystal (DCC) X-ray optics, this technique enables high-sensitivity, compact, low-power, safe, reliable, and rugged analyzers for insitu, online measurements in industrial process, clinical, and field settings. This new optic-enabled M $\mu$ EDXRF technique is known as high-definition X-Ray fluorescence (HD XRF). Selected applications of HD XRF are described in this paper including air particulate analysis, analysis of body fluid contamination at ppb levels, elemental mapping of brain tissue and bone samples, as well as analysis of toxins in toys and other consumer products.

Copyright ( 12008 Walter M. Gibson et al. This is an open access article distributed under the Creative Commons Attribution License, which permits unrestricted use, distribution, and reproduction in any medium, provided the original work is properly cited.

\section{Introduction}

The need for sensitive, easy-to-use, accurate, portable, and nondestructive multielement analyzers for environmental, medical, industrial, and scientific uses has become increasingly important. Recent development of a high-definition XRay fluorescence (HD XRF) platform shows promise to meet this need. The principles and techniques for this HD XRF system are discussed in a companion paper [1]. In summary, state-of-the-art doubly curved crystal (DCC) x-ray optics enables high-sensitivity, compact, low-power, safe, reliable, and rugged analyzers for insitu, online, measurements in industrial process, clinical, and field settings. A schematic diagram of an HD XRF system is shown in Figure 1. Selected applications of HD XRF are presented in this paper.

\section{Trace Element Analysis}

\subsection{Environmental Particulate Analysis}

Air quality has long been identified as a major public health issue and is the object of ongoing study and remediation efforts. Epidemiologic studies dating as early as the 1930s and extending through the 50s and 60s [2-4] indicate that human exposure to high concentrations of particulate matter (PM) results in serious health effects including higher death rates, particularly in children, elderly, and other physically vulnerable members of society. As a result, the Environmental Protection Agency (EPA) has regulated the levels of ambient PM since 1971. More recent studies indicate that even small, short-term increases in PM levels can induce significant increases in both mortality and morbidity from respiratory and cardiovascular diseases $[5,6]$. Extensive air particulate monitoring (Federal Reference Method (FRM)) networks have been established with increased attention to finer particles (ambient particles are defined by their aerodynamic diameter: ultrafine, less than $1 \mu \mathrm{m}$; fine, $1-2.5 \mu \mathrm{m}$; and coarse, $2.5-10 \mu \mathrm{m}$, undifferentiated or total PM is sometimes collected which includes particles up to $\sim 50 \mu \mathrm{m}$ ). Since 1978 , the National Ambient Air Quality Standards (NAAQS) have regulated "inhalable" particles, sorted into particles with an aerodynamic diameter of $2.5 \mu \mathrm{m}$ or less $\left(\mathrm{PM}_{2.5}\right), 10 \mu \mathrm{m}$ or less $\left(\mathrm{PM}_{10}\right)$, or $2.5-10 \mu \mathrm{m}\left(\mathrm{PM}_{2.5-10}\right)$. Medical and other effects tend to be studied in terms of these size designations, 
with $\mathrm{PM}_{2.5}$ (and more recently $\mathrm{PM}_{1.0}$ or even $\mathrm{PM}_{0.1}$ ) singled out for particular attention.

General air particulate monitoring in the (US), is concentrated principally in two networks: National Air Monitoring Stations (NAMS), and State and Local Air Monitoring Stations (SLAMS). These systems include over 5,000 monitors at approximately 3,000 sites. Recently, EPA has proposed combining these and other networks into the NCore Monitoring Network, a three-tier system of monitoring sites [7]. Of these, Level 2 would be a national network that would provide near real-time, high-quality $\mathrm{PM}_{2.5}$ data plus routine chemical speciation.

The Center for Disease Control has published two of three projected National Reports on Human Exposure to Environmental Chemicals, the latest in 2005 [8]. Along with a large number of metabolites of organophosphate pesticides, cotinine, phthalates, aromatic hydrocarbons dioxins, herbicides, and so forth, a large number of metals such as $\mathrm{Pb}, \mathrm{Cd}, \mathrm{Hg}, \mathrm{Co}, \mathrm{U}, \mathrm{Sb}, \mathrm{As}, \mathrm{Ba}, \mathrm{Be}, \mathrm{Cs}, \mathrm{Mo}, \mathrm{Pt}, \mathrm{Th}$, and $\mathrm{W}$ were included. The route of most of these toxins into the body is by ingestion and for some of them, the origin has been identified as principally geological, carried to humans or to the food chain through ground water. Others, however, have been associated with PM contamination. For example, $\mathrm{Hg}$, which is a major health danger for children, is known to be introduced into the environment almost exclusively by combustion of coal. Although distribution and concentration in the food chain and subsequent ingestion is believed to be the most serious pathway to humans, the initial role of PM contamination as a primary source is important. $\mathrm{PM}$ involvement is also believed to be connected with $\mathrm{Pb}$ and Cd toxicity.

Little information is available on the direct and indirect involvement of PM on elemental (especially transition and heavy metal) toxicity. Therefore, direct, sensitive, and remote monitoring of trace metal PM contamination is of great importance.

In addition to possible toxic involvement, elemental speciation of PM in nearly real time can provide a sensitive signature on the sources of PM. Therefore, the shortest time resolution and widest possible distribution of trace element PM speciation monitors are important. The remarkable sensitivity, small size, low power, and low cost of HD XRFbased analysis has resulted in EPA and New York State Environmental Research Authority (NYSERDA) funding for development of a remote, near real-time HD XRF analyzer for PM speciation applications (EPA EP-D-06-089, NYSERDA Agreement no. 9392 PON944).

In addition to air particulate monitoring and analysis of general urban and remote air particulate exposure, there is intense current interest in determination of personal exposure to airborne particulate contamination. Two large government initiatives, the Genetics-Environment Initiative (GEI) [9], and the National Children's Study (NCS) [10], have been recently announced by the Department of Health and Human Services. These initiatives include development of personal air particulate samplers with timeand even position-resolved measurement of the amount and composition of the personal exposure of targeted

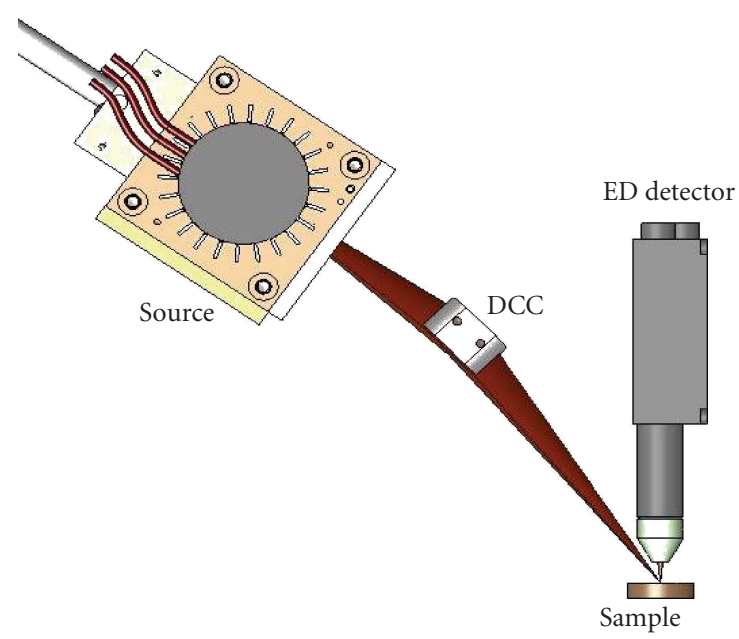

FIgURE 1: Schematic diagram of an HD XRF system. The source is a small-spot, low-power $(<100 \mathrm{~W})$ electron bombardment source which with a doubly curved crystal (DCC) optic and an energy dispersive (ED) detector comprise HD XRF.

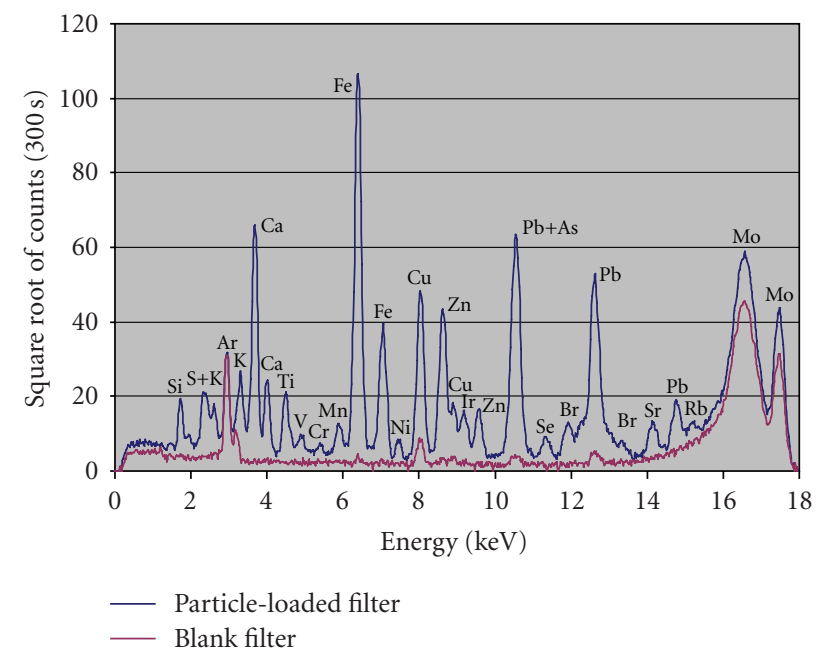

FIGURE 2: HD XRF spectra from total air particulate sample and background filter collected by miniature personal air particulate sampler with air collection volume of $0.500 \mathrm{~L} / \mathrm{min}$ with a monochromatic Mo K $\alpha$ excitation beam (courtesy of RTI, Raleigh, NC, USA).

subjects. Miniaturization of air particulate collectors involves significantly reduced sampled air volumes and sample size both of which virtually preclude use of current laboratorybased elemental analysis techniques [11]. The high sensitivity of HD XRF is well suited for such analyses. Techniques and instruments for this purpose are being actively explored by X-Ray Optical Systems, Inc. (XOS) (East Greenbush, NY, USA) and Research Triangle Inc. (RTI) (Raleigh, NC, USA). An HD XRF spectrum for a small-area filter collected air particulate sample is shown in Figure 2. This spectrum illustrates the ability of HD XRF to measure many elements at the same time. 
TAble 1: Mass per unit area of elements shown in Figure 2 from FP analysis [1]. Uncertainties shown are statistical Poisson statistics from peak intensities.

\begin{tabular}{lcccccccc}
\hline Element & $\mathrm{Pb}$ & $\mathrm{Fe}$ & $\mathrm{Zn}$ & $\mathrm{Ti}$ & $\mathrm{Ca}$ & $\mathrm{Cu}$ & $\mathrm{As}$ & $\mathrm{K}$ \\
\hline Meas. Data $\left(\mathrm{ng} / \mathrm{cm}^{2}\right)$ & $2080 \pm 29.3$ & $7578 \pm 80.3$ & $693 \pm 7.2$ & $763 \pm 7.9$ & $12096 \pm 127$ & $971 \pm 9.8$ & $139 \pm 1.8$ & $2080 \pm 29.3$ \\
\hline & & & & & & & \\
\hline Element & $\mathrm{Cr}$ & $\mathrm{Mn}$ & $\mathrm{Ni}$ & $\mathrm{V}$ & $\mathrm{Rb}$ & $\mathrm{Sr}$ & $\mathrm{Br}$ & \\
\hline Meas. Data $\left(\mathrm{ng} / \mathrm{cm}^{2}\right)$ & $42+0.8$ & $139 \pm 1.8$ & $55 \pm 0.9$ & $21 \pm 0.7$ & $7 \pm 0.7$ & $44 \pm 1.4$ & $35 \pm 0.9$ & \\
\hline
\end{tabular}

A tabulation of collected mass values for this sample from fundamental parameter (FP) analysis [1] is shown in Table 1. It is instructive to comment on some features of Figure 2 and Table 1 as follows. (1) The measured HD XRF intensities are plotted as the square root of the number of measured counts. This is convenient because it allows a large range of intensities to be shown on the same graph and it also makes it easy to estimate the statistical uncertainty from the Poisson statistics in the measurement. For example, the sqrt of the Fe $\mathrm{K} \alpha$ peak is $\sim 130$ so the statistical uncertainty is $130 /(130)^{2}=1 / 130=0.008$ or $0.8 \%$, and for the Ti K $\alpha$ peak it is $1 / 20=5 \%$. (2) The background measurement (shown in red), taken by shifting the sample so that the exciting beam is incident on a part of the filter displaced from the welldefined area on which the particles were collected, shows a low and nearly constant background. It also shows the Rayleigh (coherent) and Compton (incoherent) scattering of the incident monochromatic Mo $\mathrm{K} \alpha(17.6 \mathrm{keV}) \mathrm{X}$-ray beam. The difference in the Rayleigh and Compton scattering between the observed particulate sample and the measured background filter sample is due to scattering from the observed (and unobserved) elemental constituents. This can be used to estimate the mass of low-mass elements in the sample [1]. (3) It is seen in Figure 2 that the Argon (Ar) peak is the same for the sample and background measurement. This peak is due to excitation of Ar in the volume of the air path in front of the sample that is exposed to both the exciting beam and the detector measurement cone. This does not change when the position of the filter is moved and provides a very convenient internal energy and intensity standard that shows that the geometry, incident beam intensity, and the detector response function were constant for the two measurements. (4) Finally, it is observed that three small peaks corresponding to $\mathrm{Fe}, \mathrm{Cu}$, and $\mathrm{Pb}$ are evident in the background spectrum. The Fe and $\mathrm{Cu}$ peaks are artifacts arising from small levels of contamination in the Aluminum collimating aperture in front of the detector and the $\mathrm{Pb}$ has been tentatively traced to contamination of the filter from handling and storage [11].

The same RTI collector used to collect the total particulate fraction in a small $(2 \mathrm{~mm})$ spot on the filter used for the measurement shown in Figure 2 also collected a more biologically important $\mathrm{PM}_{2.5}$ fraction in a larger spot on a different filter. The mass collected in this fraction is much smaller and the collection was over a larger area, $\sim 10 \mathrm{~mm}$ diameter. Measurement with a nearly normal incident beam as done for Figure 2 would require longer measurement time in order to obtain useful measurement statistics. The small

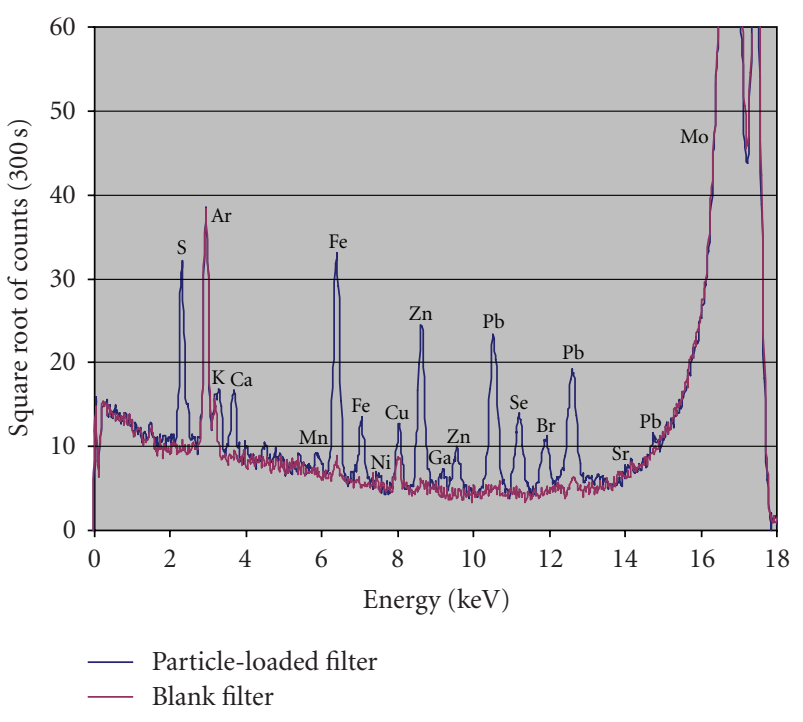

FIGURE 3: $\mathrm{PM}_{2.5}$ fraction from miniature personal particulate environmental analyzer. Grazing angle HD XRF spectrum.

analyzer incident beam spot leads to less efficient use of the exciting beam and lower measurement efficiency for large sample areas. However, changing the incident beam direction to a more glancing angle makes a significant difference. This is possible because of the small divergence of the incident beam. Figure 3 shows the spectrum and Table 2 shows the calculated masses for observed constituents for an incident angle of five degrees.

The important question is the following. How reliable are these results? To check this, measurements were made with an NIST air particulate standard SRM 2783. This standard was developed for standard particulate collection on $2.4 \mathrm{~cm}$ diameter filters. Measured and reference results are shown in Table 3. The measured and reference values are within the NIST-reported uncertainty in the reference and the statistical uncertainty in the measurement except for $\mathrm{Ca}$ and $\mathrm{K}$ for which the measured values are $\sim 26 \%$ and $43 \%$ lower than the reference values, respectively. The reasons for these discrepancies are not clear but may arise from a systematic error in the excitation probability adjustment (which is very large for such low $\mathrm{Z}$ elements for the Mo K $\alpha$ excitation beam) or possibly from particle size effects, air absorption, or medium absorption (from penetration of the captured particles into the filter) due to the low XRF energy for these elements. 
TAble 2: Mass per unit area of elements shown in Figure 3 from FP analysis [1]. Uncertainties shown are statistical Poisson statistics from peak intensities.

\begin{tabular}{|c|c|c|c|c|c|c|c|c|}
\hline Element & $\mathrm{Pb}$ & $\mathrm{Fe}$ & $\mathrm{Zn}$ & $\mathrm{Ti}$ & $\mathrm{Ca}$ & $\mathrm{Cu}$ & As & $\mathrm{K}$ \\
\hline Meas. Data $\left(\mathrm{ng} / \mathrm{cm}^{2}\right)$ & $85.4 \pm 1.2$ & $237.1 \pm 3.1$ & $62.6 \pm 1.0$ & $25.6 \pm 0.9$ & $166.4 \pm 2.7$ & $11.4 \pm 0.7$ & $5.7 \pm 0.9$ & $204.3 \pm 3.1$ \\
\hline Element & $\mathrm{Cr}$ & $\mathrm{Mn}$ & $\mathrm{Ni}$ & $\mathrm{V}$ & $\mathrm{Sr}$ & $\mathrm{Br}$ & Se & \\
\hline Meas. Data $\left(\mathrm{ng} / \mathrm{cm}^{2}\right)$ & $8.5 \pm 1.0$ & $10.3 \pm 0.9$ & $2.3 \pm 0.7$ & $2.0 \pm 0.7$ & $1.8 \pm 0.7$ & $8.5 \pm 0.9$ & $14.2 \pm 1.0$ & \\
\hline
\end{tabular}

TABLE 3: Reference data and measured data of air particulate on filter media from NIST (SRM 2783) with power of $50 \mathrm{kV} 25 \mathrm{~W}$, measurement time, 2 hours.

\begin{tabular}{|c|c|c|c|c|c|c|c|}
\hline & As & $\mathrm{Ca}$ & $\mathrm{Cr}$ & $\mathrm{Cu}$ & $\mathrm{Fe}$ & $\mathrm{K}$ & $\mathrm{Mn}$ \\
\hline Ref. data $\left(\mathrm{ng} / \mathrm{cm}^{2}\right)$ & $1.18 \pm 0.12$ & $1325.3 \pm 170.7$ & $13.6 \pm 2.5$ & $40.6 \pm 4.2$ & $2660.6 \pm 160.6$ & $530.1 \pm 52.2$ & $32.1 \pm 1.2$ \\
\hline Meas. Data $\left(\mathrm{ng} / \mathrm{cm}^{2}\right)$ & $1.25 \pm 0.19$ & $979.3 \pm 10.5$ & $11.9 \pm 0.9$ & $36.9 \pm 1.0$ & $2516.6 \pm 26.2$ & $302.2 \pm 5.5$ & $35.3 \pm 0.7$ \\
\hline & $\mathrm{Ni}$ & $\mathrm{Pb}$ & $\mathrm{Rb}$ & $\mathrm{Ti}$ & $\mathrm{V}$ & $\mathrm{Zn}$ & \\
\hline Ref. data $\left(\mathrm{ng} / \mathrm{cm}^{2}\right)$ & $6.8 \pm 1.2$ & $31.8 \pm 5.4$ & $2.4 \pm 0.6$ & $149.6 \pm 24.1$ & $4.9 \pm 0.6$ & $179.7 \pm 13.1$ & \\
\hline Meas. Data $\left(\mathrm{ng} / \mathrm{cm}^{2}\right)$ & $7.7 \pm 0.3$ & $33.8 \pm 0.9$ & $2.7 \pm 0.2$ & $130.7 \pm 2.9$ & $5.4 \pm 0.2$ & $172.5 \pm 1.8$ & \\
\hline
\end{tabular}

Conventional air particulate samplers use a sampling volume of $14.6 \mathrm{~L} / \mathrm{min}$ onto filters typically $2.4 \mathrm{~cm}$ diameter. This has, in part, been motivated by direct-excitation XRF analysis that has a low flux per unit area and cannot concentrate the X-ray beam. The long measurement time was necessitated by the small spot size and the large collection area for the standard. Even so, the excellent S/B ratio allows statistically meaningful measurements and shows good agreement over a wide range of elements.

Personal environmental monitors needed for large new national health initiatives such as the GEI [9] and NCS [10] will require lower collection volumes (perhaps 0.5$1 \mathrm{~L} / \mathrm{min}$ ), therefore, smaller pumps and lower power, and will involve much smaller filter or impact collector areas, in part to allow many collection positions on the same collecting substrate. New approaches for concentration of the aerosol flow stream are being explored in order to achieve desirable collector loading for shorter collection times. Because of its high sensitivity for measurement of low-sampling area, HD XRF may be an enabling analysis technology for such systems. This could result not only in personal air particulate monitoring for biologically interesting $\mathrm{PM}_{2.5}$, $\mathrm{PM}_{1}$, or even $\mathrm{PM}_{0,2}$ constituents, but also for smaller, lessexpensive, and higher-sensitivity rural, urban, and workplace monitoring in nearly real time and also for stack- or exhaustemission monitoring. Such possibilities are currently under investigation.

It should be noted that the most desirable quantitative information from air particulate studies is the concentration per unit volume of air sampled. This can be obtained from the measured mass per unit area on the sampling medium by application of information on the sampling time, the amount of air per unit time through the sampler, and any necessary corrections for capture and retention efficiency of particular elements on the sampling medium.
These air particulate measurements were chosen to illustrate the broad elemental range and high sensitivity of HD XRF as well as the quantitative application for thin samples in general. These properties are also valuable for other important applications.

\subsection{Trace Element Measurements in Bulk Materials}

A much broader range of applications for HD XRF other than air particulate measurements includes trace and major constituent concentration measurements in natural, manufactured, and environmental materials for forensic, environmental, industrial, health, regulatory, and other applications. We will not attempt to review all current and potential applications but will indicate the current status for some representative cases. As noted in the FP calculation discussion in [1], after thin samples, it is most straightforward to obtain quantitative results for homogeneous samples that are infinitely thick to the incident X-ray beam and/or the fluorescence X-rays. This includes many important applications such as measurements of trace elements in liquids such as water, fuel, and body fluids, and in homogeneous solid materials such as plastics or metals used in consumer products of interest for environmental and medical studies. For thick samples, additional factors such as incident $\mathrm{X}$ ray and fluorescent $\mathrm{X}$-ray absorption, X-ray scattering, and secondary excitation effects must be taken into account (1).

\subsubsection{Ultratrace Elements in Body Fluids}

Measurements of the composition of body fluids (urine, blood, plasma) are among the most ubiquitous and powerful tools for disease detection and control. Simple physical 
measurements such as turbidity, sedimentation rate, color, and clarity, as well as sophisticated measurements of cholesterol, glucose, cell type, prostate-specific antigen (PSA), and so forth, are used to indicate current or potential disease or disorder. Self-testing is routinely used as a primary control guide for diseases such as diabetes. One class of measurement, less routinely applied but of increasing importance, is determination of trace element concentrations. Measurement of toxic metals, such as lead, cadmium, and arsenic, or radioactive isotopes is carried out when exposure to these materials is suspected. In addition, it is increasingly recognized that the appearance of even common metals in places where they should not be, such as iron in urine or manganese in blood, can indicate organ malfunction or pathogen-initiated disease. In some cases, absence or low levels of some elements such as zinc or selenium can signal danger. Often, the concentration level of trace elements of significance is in the range of 10-100 part-per-billion (ppb) and simple, fast measurement techniques at this level of sensitivity are not readily available.

In an NIH-supported study (NIH 2R44RR021797-02), development of an HD XRF-based analyzer for measurement of trace elements of importance for understanding and potential diagnosis and treatment of neurodegenerative diseases has recently begun at XOS in collaboration with the Alzheimer's Center (Albany Medical Center, Albany, NY, USA) and the Wadsworth Center (New York State Department of Health, Albany, NY, USA). The object of this study is a clinically based analyzer for rapid, nondestructive analysis of trace element concentrations at ppb levels. Currently, only complex and expensive chemical analysis such as inductively coupled plasma mass spectroscopy (ICPMS) is capable of such measurements at the low ppb levels required [12]. This results in expense and delay (typically up to three weeks) such that desired analyses are often not carried out for diagnostic evaluation. Furthermore, the rapid results needed to monitor chelation therapy are impractical. The goal of this funded program is to permit inexpensive and accurate measurements of trace metals such as $\mathrm{Fe}, \mathrm{Cu}$, and $\mathrm{Zn}$ at the clinical point of care at concentration levels less than $10 \mathrm{ppb}$. Preliminary measurements have already shown good agreement with ICP-MS at levels as low as $40 \mathrm{ppb}$ as shown in Figure 4 and Table 4. In addition to Alzheimer's Disease and other neurodegenerative disorders that are the focus of the current study [13,14], such measurements are important to a variety of metabolic disorders such as Wilson's disease (a copper overload disease) [15], hemochromatosis (a family of Fe overload disorders) [16], and toxic effects of $\mathrm{Pb}$ [17], As [18], $\mathrm{Hg}$ [19], $\mathrm{Cd}$ [20], and $\mathrm{Sb}$ [21]. It is expected that such point-of-care analyzers will also be important for renal diseases and a variety of autoimmune diseases. It is interesting to note that for many of these cases, the elements of interest are not the traditional toxins but are often bioessential elements, which makes the broad elemental range of HD XRF particularly valuable.

Small peaks corresponding to $\mathrm{Au}, \mathrm{Cu}$, and $\mathrm{Zn}$ are observed in Figure 3. These are all due to detector-related artifacts. The Au is from secondary excitation of $\mathrm{Au}$ in the electrode on the front face of the detector and the $\mathrm{Cu}$ and

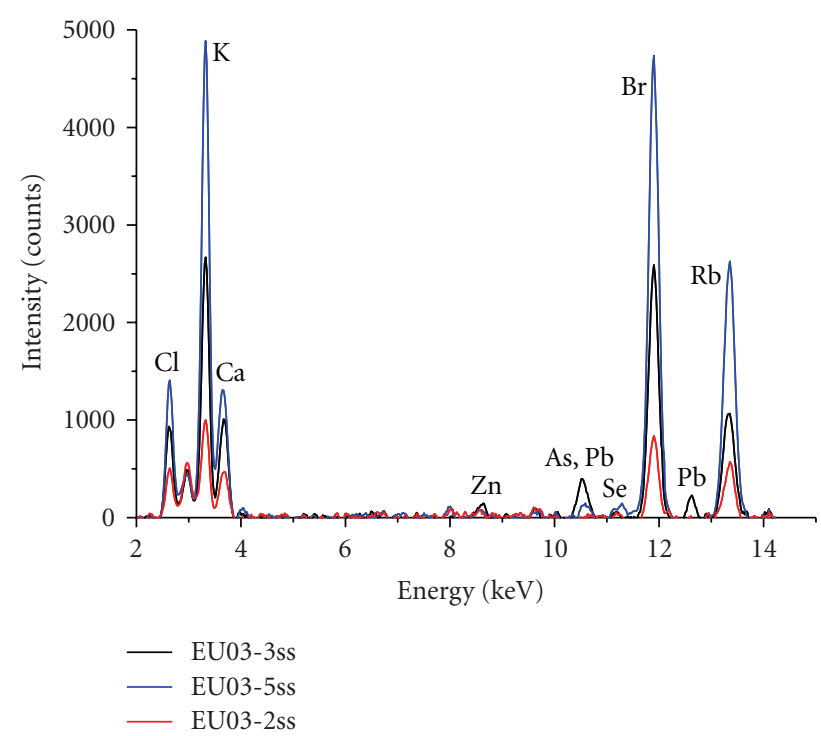

(a)

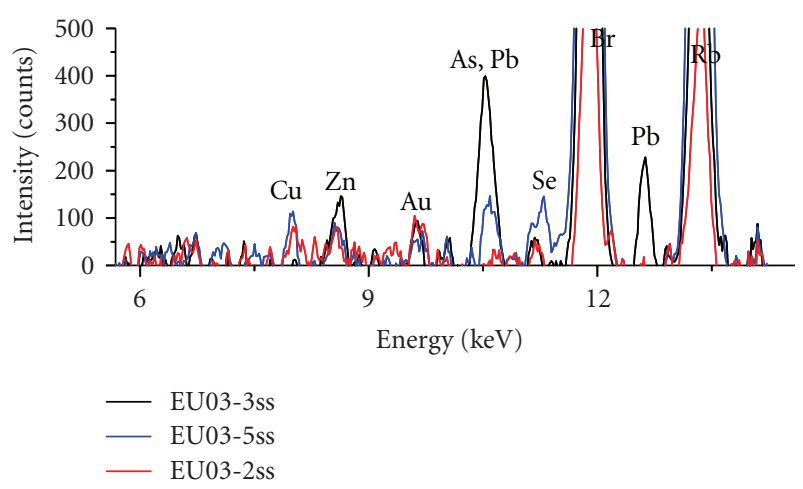

(b)

FIGURE 4: HD XRF spectra for three standard urine samples. (b) is an expanded part of (a). Measurement time was 1600 seconds with a source power of 40 Watts with an Mo X-Beam source of the type discussed in [1].

Zn have been identified as secondary excitation of impurities in the Aluminum collimator in front of the detector. These measurements were taken with a preliminary prototype system. The NIH-funded project, which started in October 2007, is designed to improve the measurement sensitivity to allow minimum quantifiable limits for $\mathrm{Pb}, \mathrm{As}, \mathrm{Zn}, \mathrm{Cu}$, and Fe down to $5 \mathrm{ppb}$ or less. This will include application of multiple optic excitation as well as detector resolution, counting rate, and artifact removal improvements. No other laboratory-based multielement XRF system can achieve such low detection limits.

The detection limits for $\mathrm{Pb}$ and As in urine was estimated based on the above preliminary data. The minimum detection concentration is given by

$$
\mathrm{MDC}=\frac{3 \sqrt{\text { Background }}}{\text { Signal }} W_{i}=\frac{3 \sqrt{B}}{S \sqrt{t}} W_{i}=\frac{3 \sqrt{B / S}}{\sqrt{S \times t}} W_{i},
$$


TABLE 4: Measured As and $\mathrm{Pb}$ levels in five reference urine samples compared with the results of an interlaboratory study by ICP-MS measurements.

\begin{tabular}{|c|c|c|c|c|}
\hline \multirow{2}{*}{ Sample } & \multicolumn{2}{|c|}{ As $(\mu \mathrm{g} / \mathrm{L}, \mathrm{ppb})$} & \multicolumn{2}{|c|}{$\mathrm{Pb}(\mu \mathrm{g} / \mathrm{L}, \mathrm{ppb})$} \\
\hline & HD XRF & ICP-MS & HD XRF & ICP-MS \\
\hline EU03-1 & $<35$ & $11.8 \pm 2.1$ & $80 \pm 25$ & $79.4 \pm 4.4$ \\
\hline EU03-2 & $<35$ & $3.2 \pm 0.9$ & $<40$ & $<0.7$ \\
\hline EU03-3 & $154 \pm 15$ & $158.9 \pm 7.7$ & $524 \pm 25$ & $528 \pm 26$ \\
\hline EU03-4 & $40 \pm 12$ & $56.8 \pm 3.0$ & $212 \pm 20$ & $224.8 \pm 8.3$ \\
\hline EU03-5 & $104 \pm 18$ & $114.8 \pm 5.0$ & $<40$ & $5.2 \pm 1.5$ \\
\hline
\end{tabular}

where $B$ is the background count rate in cps, $S$ is the signal count rate in cps, $t$ is the measurement time in seconds, and $W_{i}$ is the reference sample weight concentration. For the sample EU03-5, the As net counting rate was measured to be $1.2 \mathrm{cps}$ and the background counting rate was $25 \mathrm{cps}$. Therefore, the detection limits for 1600 seconds for As $=3 \times$ $5 \times 117 / 1.2 / 40 \sim 36 \mathrm{ppb}$. Similarly, detection limits for $\mathrm{Pb}$ were found to be about $45 \mathrm{ppb}$ for 1600 -second measurements with this early prototype system based on the signal and background level of sample EU03-3.

\subsubsection{Toxins in Toys and Other Consumer Products}

There is a great deal of interest in control of toxic elements, particularly Lead, in toys, children's play equipment, furniture, and all items that could contribute to exposure of children to harmful substances. In addition, the European Union has, under the EU directives: Restriction on the use of certain Hazardous Substances (RoHS) (2002/96/EG) and Waste Electrical and Electron Equipment (WEEE) (2002/95/EG), restricted the amount of a number of elements and compounds in electronic materials and electrical equipment provided to the European market as of June, 2006. These include, $\mathrm{Pb}, \mathrm{Hg}, \mathrm{Cd}, \mathrm{Cr}^{+6}$, and certain compounds of $\mathrm{Br}$. In addition $\mathrm{Ba}, \mathrm{Sb}$, and Se have been identified as potentially harmful at high levels. These elements are also of concern for toys and children's and household furniture, as well as other consumer products. Many of the items of interest are made of molded or painted plastic and often of painted wood.

\subsubsection{Homogeneous solids}

Analysis of homogeneous plastic materials can be carried out by the same FP approach as that used for the liquid samples discussed in the previous subsection. Comparisons of such analyses for homogeneous polyethylene (PE) plastic standard samples are shown in Figure 5 and Table 5.

The analytical simulation fundamental parameter (SFP) analysis [1] used in this example is fast but not automated. It requires fitting of the peak intensity for both the Rayleigh and Compton scattering peaks (even though the shape of the Compton peak is not matched) and for the major peaks in the spectrum for each observed element. The simulation takes into account secondary excitation, peak overlap, and absorption effects even for unobserved elements

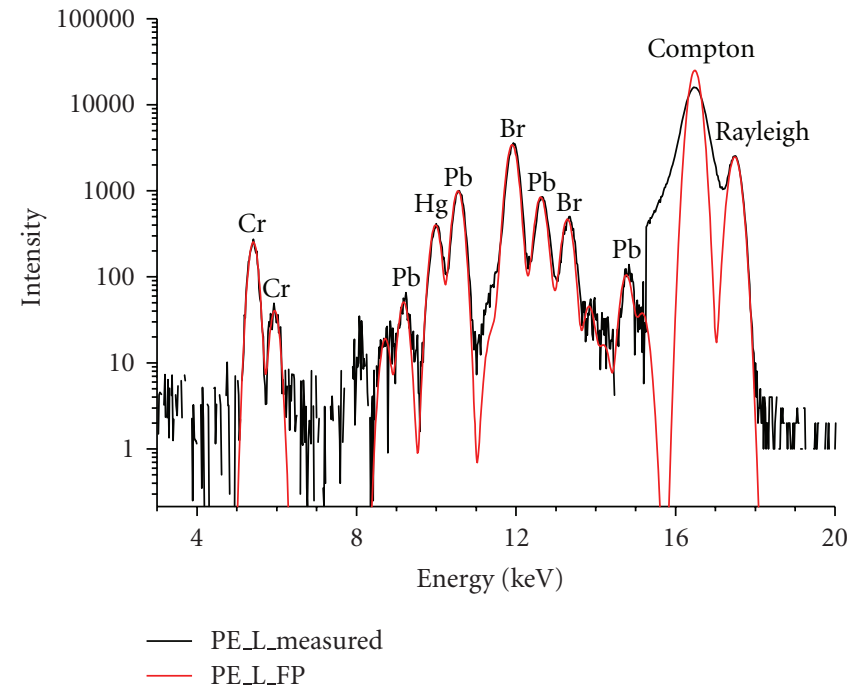

FIGURE 5: HD XRF spectrum from polyethylene standard PE 5398 L sample and analytical simulated spectrum from fundamental parameter analysis. A background subtraction was made for the spectrum below $15.2 \mathrm{keV}$.

(such as $\mathrm{H}, \mathrm{C}, \mathrm{O}$, and $\mathrm{N}$ ). An automated reverse fundamental parameter (RFP) analysis is more desirable and is possible for simple homogeneous samples as shown in what follows. This case is shown because the SFP analysis is still available for quantitative concentration determinations even while the more complex RFP algorithms are being developed (especially for multilayer samples).

Plastic toys and other plastic-consumer products are principally made from polyethylene (PE), polyethylene terephalate (PET), or acrylonitrile butadiene styrene (ABS). These plastic matrices are very similar in their behavior to FP analysis. Figure 6 shows HD XRF spectra for two elementally doped ABS standards with markedly different $\mathrm{Pb}$ content, and Table 6 shows the results of automated RFP analysis for four NMIJ standards. The measurement time for each measurement was 120 seconds and the analysis time was $<10$ seconds. As with Figure 5, it is observed that the Rayleigh and Compton scattering peaks are very strong for these low $\mathrm{Z}$ matrices. Another plastic used extensively for consumer products is polyvinyl chloride (PVC). 
TABLE 5: Reference and measured values for three polyethylene standards. The experimental uncertainty (at 95\% level) includes estimated systematic uncertainty plus Poisson counting statistical error.

\begin{tabular}{llccccc}
\hline Sample & & $\mathrm{Cr}$ & $\mathrm{Hg}$ & $\mathrm{Pb}$ & $\mathrm{Br}$ & Error \\
\hline \multirow{2}{*}{ PE_5398_N } & Reference & 1001 & 1000 & 1000 & 500 & $4 \%(95 \%$ level $)$ \\
& Measured & 1020 & 950 & 981 & 442 & $10 \%(95 \%$ level $)$ \\
PE_H_18A & Reference & 1000 & 1100 & 1200 & 1100 & $4 \%(95 \%$ level $)$ \\
\multirow{2}{*}{ PE_L } & Measured & 1020 & 1150 & 1220 & 1090 & $10 \%(95 \%$ level $)$ \\
& Reference & 400 & 200 & 400 & 500 & $4 \%(95 \%$ level $)$ \\
& Measured & 401 & 185 & 419 & 508 & $10 \%(95 \%$ level $)$ \\
\hline
\end{tabular}

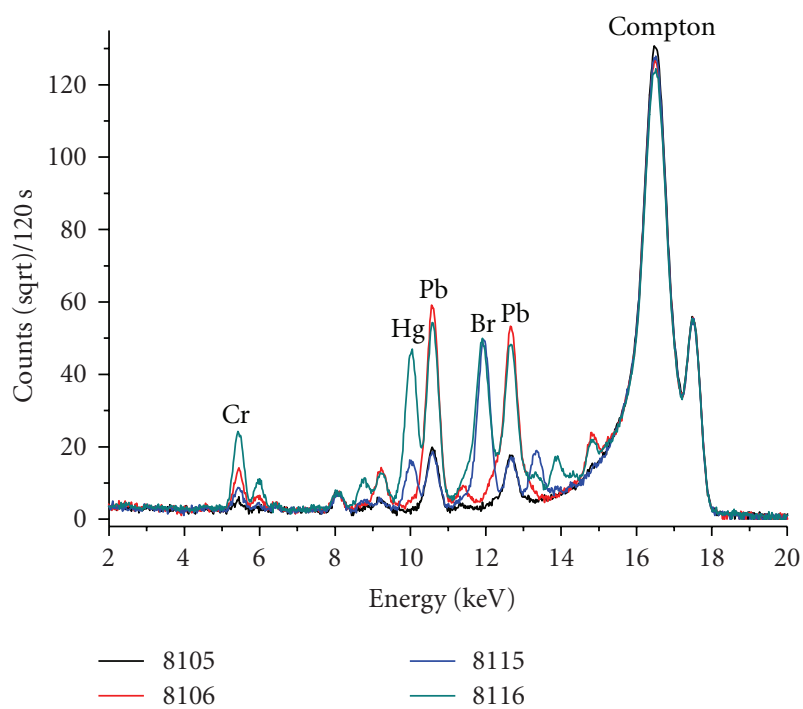

FIgURE 6: HD XRF spectra for ABS plastic standards.

Detailed discussion of the methods used to obtain concentrations shown in Tables 1-9 is given in the companion paper on HD XRF principles and techniques [1].

Even though the analysis software development is not yet completed for general matrices, it is possible for a variety of homogeneous plastic solid and homogeneous liquid samples to carry out an RFP analysis in a few seconds. The rapid analyses and the low level of detection are enabled by the use of monochromatic excitation and the high beam intensity in the HD XRF system. Analysis refinements that are underway are connected with spectrum preprocessing and background and peak overlap corrections. The minimum detection concentration calculated by (1) is shown for $\mathrm{Cr}, \mathrm{Hg}$, and $\mathrm{Pb}$ in Table 6. It can be seen that MDC values achievable by the prototype HD XRF system for toxins in homogeneous plastic products are in the low ppm range.

\subsubsection{Layered Solids}

Layered materials present a much more difficult problem, for which the analysis is at an even earlier stage of development. The special features of HD XRF of monochromatic excitation and small analysis spot size are particularly important for analysis of layered materials. It is instructive to consider a specific example that illustrates the power of HD XRF in measuring elemental concentration in layered samples. This example is a well-known promotional ceramic cup with the "I Love NY" slogan. A photograph of such a cup with HD XRF spectra for the white ceramic cup, the printed black lettering, and the printed red heart is shown in Figure 7. Superposition of the three spectra is shown in Figure 8 where the square root of the number of measured counts is used to emphasize some of the low-intensity features.

A number of features are worthy of note in the superposed spectra shown in Figure 8 and described as follows.

(i) The elastic (Rayleigh) and inelastic (Compton) scattering peaks are much lower, relative to other features than observed for plastic matrices in Figures 4 and 5. This is due to the lower concentrations of low $\mathrm{Z}$ elements (particularly hydrogen) in the ceramic cup and in the painted layers.

(ii) $\mathrm{Pb}, \mathrm{Co}, \mathrm{Fe}, \mathrm{Cr}$ are present in the black lettering but are at lower levels or absent in the white cup.

(iii) $\mathrm{Pb}$ and $\mathrm{Se}$ are present in the red heart.

(iv) $\mathrm{Ca}, \mathrm{Sr}$, and $\mathrm{Zn}$ are principle constituents of the white cup, probably as part of the ceramic which also, of course, is expected to contain oxygen, carbon, and nitrogen and may contain other major constituents such as $\mathrm{Si}$ and $\mathrm{Al}$ which are not observed.

(v) Of special note is the observation of four characteristic lines from $\mathrm{Pb}(\mathrm{Pb} \mathrm{M}, \mathrm{Pb} \mathrm{L} \alpha, \mathrm{Pb} \mathrm{L} \beta$, and $\mathrm{Pb} \mathrm{L} \gamma$ ). The relative excitation probability for these lines can be looked up from tabulated excitation tables, and absorption coefficients are also available from tabulations using the material density derived in the iterative FP calculation. Therefore, their relative observed intensities (particularly the $\mathrm{Pb} \mathrm{M}$ line) can be used in the FP analysis to determine the thickness of the black paint layer.

(vi) Similarly, attenuation of the $\mathrm{Sr}$ and $\mathrm{Zn}$ peaks can give information on the thickness of the black and red paint layers.

Taking these effects into account, by using the analytical simulation calculation, the concentration of elements in the white cup and in the black and red paint layers have been calculated and are shown in Tables 7, 8, and 9. The very high $\mathrm{Pb}$ concentration in the black lettering is of special interest. 
TABLE 6: RFP analysis for ABS plastic standards.

\begin{tabular}{|c|c|c|c|c|c|c|}
\hline \multirow{2}{*}{ Sample } & \multicolumn{2}{|c|}{$\mathrm{Cr}(\mathrm{ppm})$} & \multicolumn{2}{|c|}{$\mathrm{Hg}(\mathrm{ppm})$} & \multicolumn{2}{|c|}{$\mathrm{Pb}(\mathrm{ppm})$} \\
\hline & Reference & Measured & Reference & Measured & Reference & Measured \\
\hline NMIJ CRM 8105a & $27.5 \pm 0.5$ & $25.0 \pm 3.2$ & N/A & N/A & $108.3 \pm 1.2$ & $105.8 \pm 4.4$ \\
\hline NMIJ CRM 8106a & $268.1 \pm 2.1$ & $276 \pm 17$ & N/A & N/A & $1077 \pm 6.7$ & $1081 \pm 14$ \\
\hline NMIJ CRM 8115a & $94.3 \pm 1.1$ & $91.2 \pm 9.0$ & $93.8 \pm 2.8$ & $91 \pm 4.2$ & $94.2 \pm 1.0$ & $109.9 \pm 4.5$ \\
\hline NMIJ CRM 8116a & $944 \pm 12$ & $946 \pm 32$ & $939 \pm 27$ & $853 \pm 14$ & $941 \pm 9$ & $973 \pm 14$ \\
\hline Minimum detection concentration (MDC) & & 7.4 & & 1.4 & & 1.4 \\
\hline
\end{tabular}

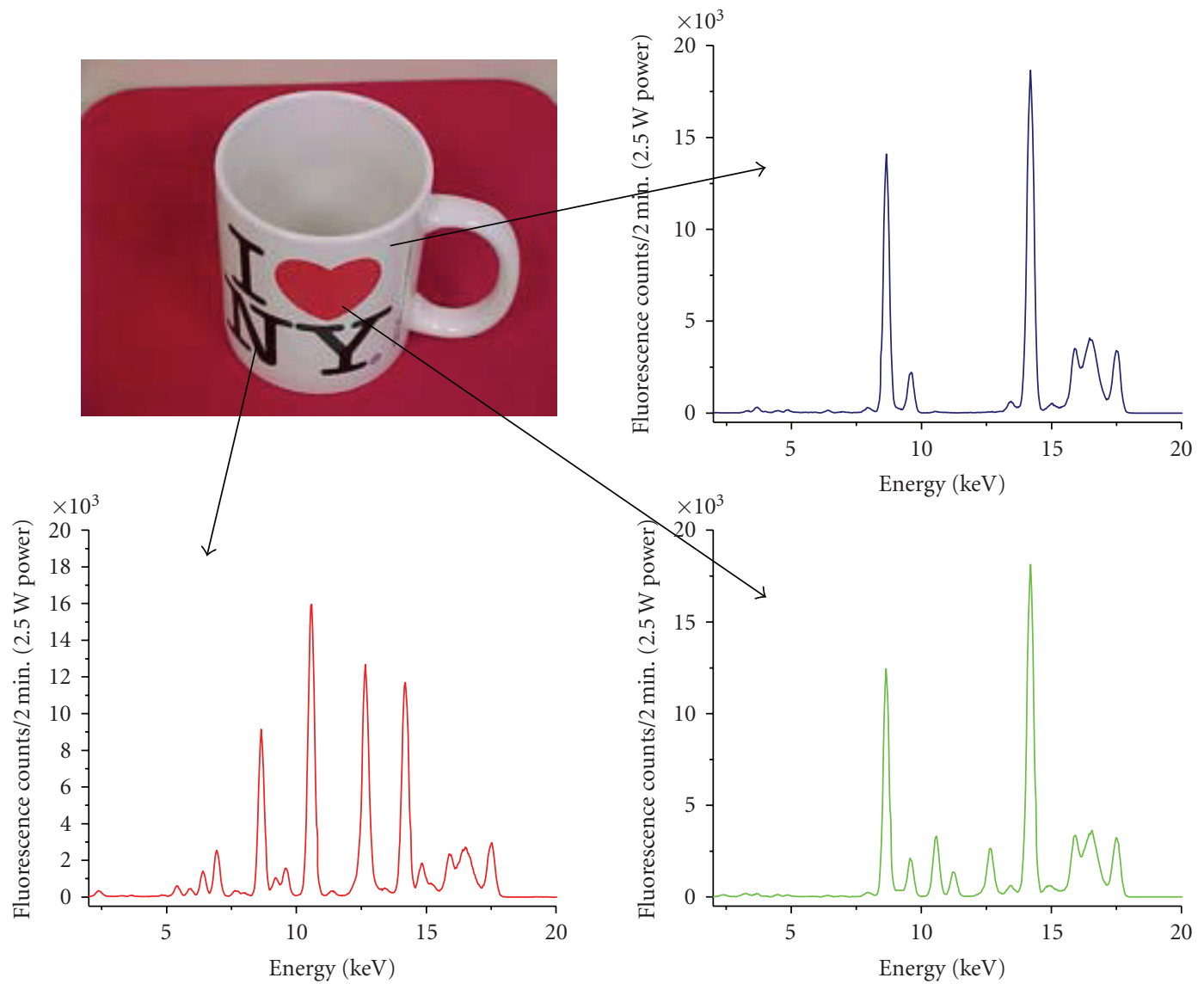

FIGURE 7: Photograph of promotional "I Love NY" cup and HD XRF spectra for the white ceramic, the black printed lettering, and the red printed heart.

The uncertainties shown are from the Poisson counting statistics.

It is clear that for single paint layers on a plastic or other substrate, it is very useful to be able to measure the substrate independently. Since the spot size for the HD XRF measurement is small $(<1 \mathrm{~mm})$, removal of the surface layer in a small 2-3 $\mathrm{mm}$ spot can give this important information without destroying or even seriously defacing the sample. General automated FP analysis for layered samples is currently being developed and we believe measurements will be able to be quantified with uncertainty of $1-5 \%$. Currently, quantification of layered samples by automated FP analysis is accurate to about $10-20 \%$.

\section{Mapping of Elemental Distributions with an HD XRF Analyzer}

The concentration and distribution in tissue of bioessential elements such as $\mathrm{Fe}, \mathrm{Cu}$, and $\mathrm{Zn}$, so-called Redox metals, have been identified as major players in cardiovascular diseases such as Friedreich's ataxia (FRDA) and of neurological diseases including Alzheimer's disease (AD), Parkinson's disease (PD), multiple sclerosis (MS), Huntington's disease (HD), aceruloplasmanemia, amyotrophic lateral sclerosis (ALS), and others. More than two dozen human nervous system disorders have been associated with oxidative tissue 
TABLE 7: Measured concentration of the black lettering from "I Love NY" cup.

\begin{tabular}{lccccccccc}
\hline Element & $\mathrm{Ca}$ & $\mathrm{Ti}$ & $\mathrm{V}$ & $\mathrm{Cr}$ & $\mathrm{Mn}$ & $\mathrm{Fe}$ & $\mathrm{Co}$ & $\mathrm{Zn}$ & $\mathrm{Pb}$ \\
\hline Concentration (\%) & $0.64 \pm 0.03$ & $0.21 \pm 0.04$ & $0.34 \pm 0.05$ & $1.79 \pm 0.02$ & $0.58 \pm 0.02$ & $2.21 \pm 0.03$ & $3.53 \pm 0.04$ & $1.68 \pm 0.02$ & $20.5 \pm 0.2$ \\
\hline
\end{tabular}

TABLE 8: Measured concentration of the red heart from "I Love NY" cup.

\begin{tabular}{lccccccccc}
\hline Element & $\mathrm{K}$ & $\mathrm{Ca}$ & $\mathrm{Ti}$ & $\mathrm{V}$ & $\mathrm{Fe}$ & $\mathrm{Cu}$ & $\mathrm{Zn}$ & $\mathrm{Se}$ & $\mathrm{Pb}$ \\
\hline Concentration (\%) & $1.98 \pm 0.02$ & $0.64 \pm 0.03$ & $0.42 \pm 0.03$ & $0.15 \pm 0.03$ & $0.07 \pm 0.02$ & $0.19 \pm 0.03$ & $0.81 \pm 0.02$ & $0.78 \pm 0.03$ & $3.69 \pm 0.04$ \\
\hline
\end{tabular}

damage in which redox metals are believed to play an important role.

Although abnormal iron deposition has been associated with many neurodegenerative diseases since the association was discovered more than 50 years ago [22], its role and origin are still not well understood. A long-term objective is to correlate the location and, if possible, the oxidation state distribution of metal deposits at a subcellular level with structural abnormalities such as betaamyloid plaque $(\mathrm{A} \beta)$, neurofibrillary tangles, and so forth. Iron staining is widely used to determine regions of iron overload, and the distribution of nonheme iron $[23,24]$ and some information about the redox state of the iron can be obtained with modified staining techniques [25]. Magnetic resonance imaging (MRI) is important for study of diseases exhibiting regionspecific brain-iron accumulation, and progress continues to be made in development of this technique as a diagnostic tool $[26,27]$. A major benefit of nondestructive HD XRF mapping of elemental distributions is that subsequent to this measurement, staining microscopy can be carried out on the same samples to study detailed correlation of metal deposits with anatomical and pathological features.

Recently, a number of Synchrotron-based micro-X-ray fluorescence $(\mathrm{S} \mu \mathrm{XRF})$ studies of brain sections from $\mathrm{AD}, \mathrm{PD}$, and other neurodegenerative diseases have been reported [28-33]. These studies have demonstrated the power of micro-X-ray fluorescence in such studies and have also shown that $\mathrm{Fe}, \mathrm{Cu}$, and $\mathrm{Zn}$ distributions are associated with $\beta$-amyloid plaque $(A \beta)$ [18]. Unfortunately, application of the Synchrotron tool is expensive and it has limited accessibility.

There are many other instances where elemental distributions play an important role. These include measurement of lead in bone, minerals in ore and stone deposits, art history, document authentication, and so forth. Only two cases (metals in brain tissue and lead in bone [24]) will be shown as examples in this paper. These have been chosen in part because of the award of an NIH grant (NIH 2R44RR02200102) to XOS for development of an instrument for these medical research applications.

A diagram of a setup for measurement of elemental distributions by HD XRF is shown in Figure 9(a). A photograph of the setup is shown in Figure 9(b). In this setup, an Oxford Mo Apogee tube was used with a power setting of $45 \mathrm{~W}$. The Apogee tube has a source spot size of $90 \mu \mathrm{m}$. An Si(220) asymmetrical DCC was used to form a focused

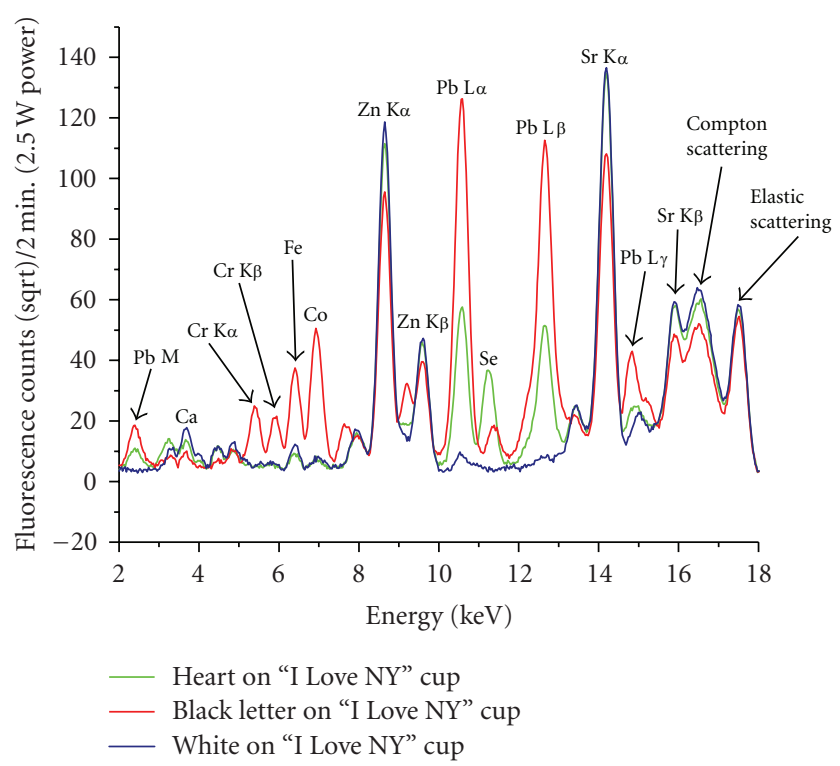

FIgURE 8: Superposition of spectra for three features on "I Love NY" promotional cup.

monochromatic Mo K $\alpha$ beam. The parameters of the $\operatorname{Si}(220)$ DCC optic are listed in Table 10. The X-ray source was demagnified to form a $50 \mu \mathrm{m}$ spot on the sample. The sample was mounted on a PC-controlled XYZ stage. The sample surface was parallel to the $\mathrm{XY}$ plane of the stage. A silicon drift detector (SDD) was used to measure the fluorescent Xrays from the sample.

A PC Window-based program was used for scanning and spectrum analysis. The program can integrate the intensity under a number of selected fluorescent peaks in the XRF spectrum. The scanning was done by moving the sample in a raster pattern. The integrated intensities for selected peaks in the X-ray fluorescence spectra versus pixel location of the sample are used for analysis and creating multielement maps.

\subsection{Scanning Measurements for Selected Samples}

\subsubsection{Scanning of Mouse Brain Sections}

Figures 10, 11, 12, 13, and 14 show the results of scanning a $100 \mu \mathrm{m}$ thick transgenic amyloid precursor protein (APP) 
TABLE 9: Measured concentration of the white substrate from "I Love NY" cup.

\begin{tabular}{lccccccccccc}
\hline Element & $\mathrm{K}$ & $\mathrm{Ca}$ & $\mathrm{V}$ & $\mathrm{Mn}$ & $\mathrm{Fe}$ & $\mathrm{Co}$ & $\mathrm{Zn}$ & $\mathrm{Rb}$ & $\mathrm{Sr}$ & $\mathrm{Ba}$ & $\mathrm{Pb}$ \\
\hline \multirow{2}{*}{ Concentration (\%) } & 1.98 & 2.52 & 0.05 & 0.03 & 0.06 & 0.02 & 1.65 & 0.02 & 0.61 & 0.98 & 0.01 \\
& \pm 0.02 & \pm 0.03 & \pm 0.03 & \pm 0.02 & \pm 0.03 & \pm 0.01 & \pm 0.02 & \pm 0.01 & \pm 0.01 & \pm 0.02 & \pm 0.01 \\
\hline
\end{tabular}

TABle 10: Asymmetrical Si(220) DCC optic parameters.

\begin{tabular}{lccccc}
\hline Crystal & Focusing E & Source-optic dist. & Optic-Focus dist. & Flux @ 45w & Measured spot size \\
\hline $\mathrm{Si}(220)$ & $17.5 \mathrm{keV}$ & $160 \mathrm{~mm}$ & $80 \mathrm{~mm}$ & $1 \times 10^{7}$ & $50 \mu \mathrm{m}$ \\
\hline
\end{tabular}

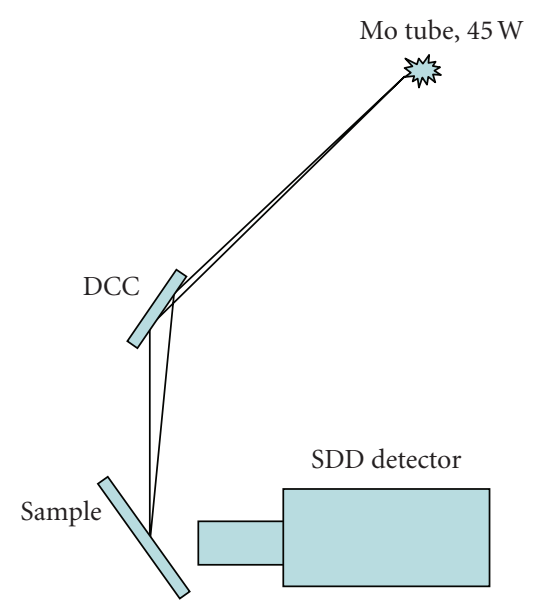

(a)

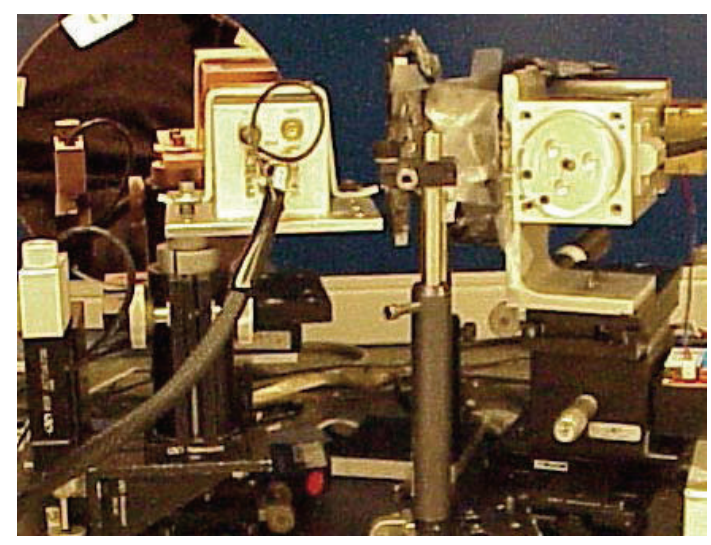

(b)

Figure 9: Schematic (a) and photograph (b) of a laboratory HD XRF setup for elemental mapping.

(sw695) mouse brain section. It should be noted that the general brain distribution scans (with all elements being measured in the same scan) were made with a beam spot of $100 \mu \mathrm{m}$ diameter by displacing the sample from the focal spot (along the beam direction), while selected area scans were with a $50 \mu \mathrm{m}$ spot size as listed in Table 10.

The $100 \mu \mathrm{m}$ thick mouse brain section was mounted on a $4 \mu \mathrm{m}$ thick Mylar film. Analysis was carried out with the same FP analysis program used for the thin air particulate

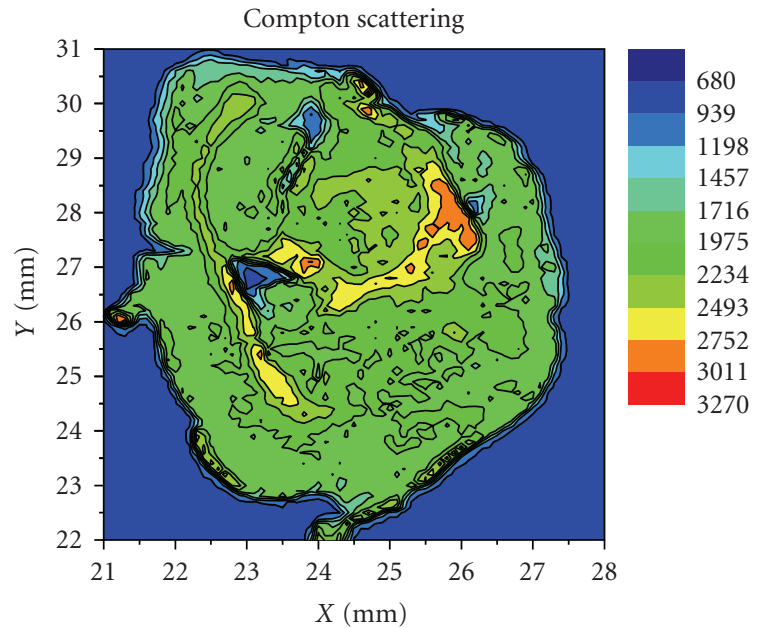

(a)

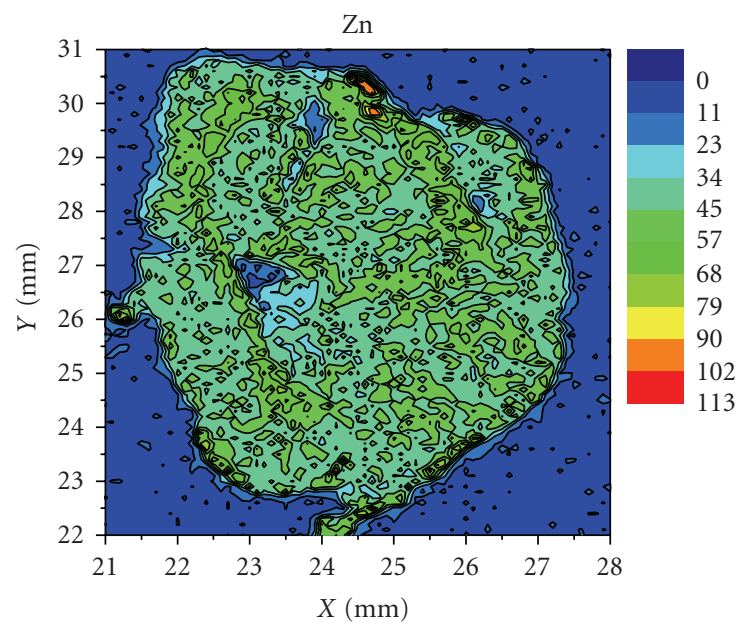

(b)

Figure 10: Raster scans for an APP mouse brain section from integration of the Compton scattering peak (a) (which shows the brain section density distribution) and the $\mathrm{Zn}$ distribution (b).

samples discussed in Section 2.1. By following the DCC focusing optic with a strongly focusing polycapillary optic, it is possible to achieve a focal spot size as small as $10 \mu \mathrm{m}$ with zooming capability to $\sim 300 \mu \mathrm{m}$ scans, allowing rapid general 

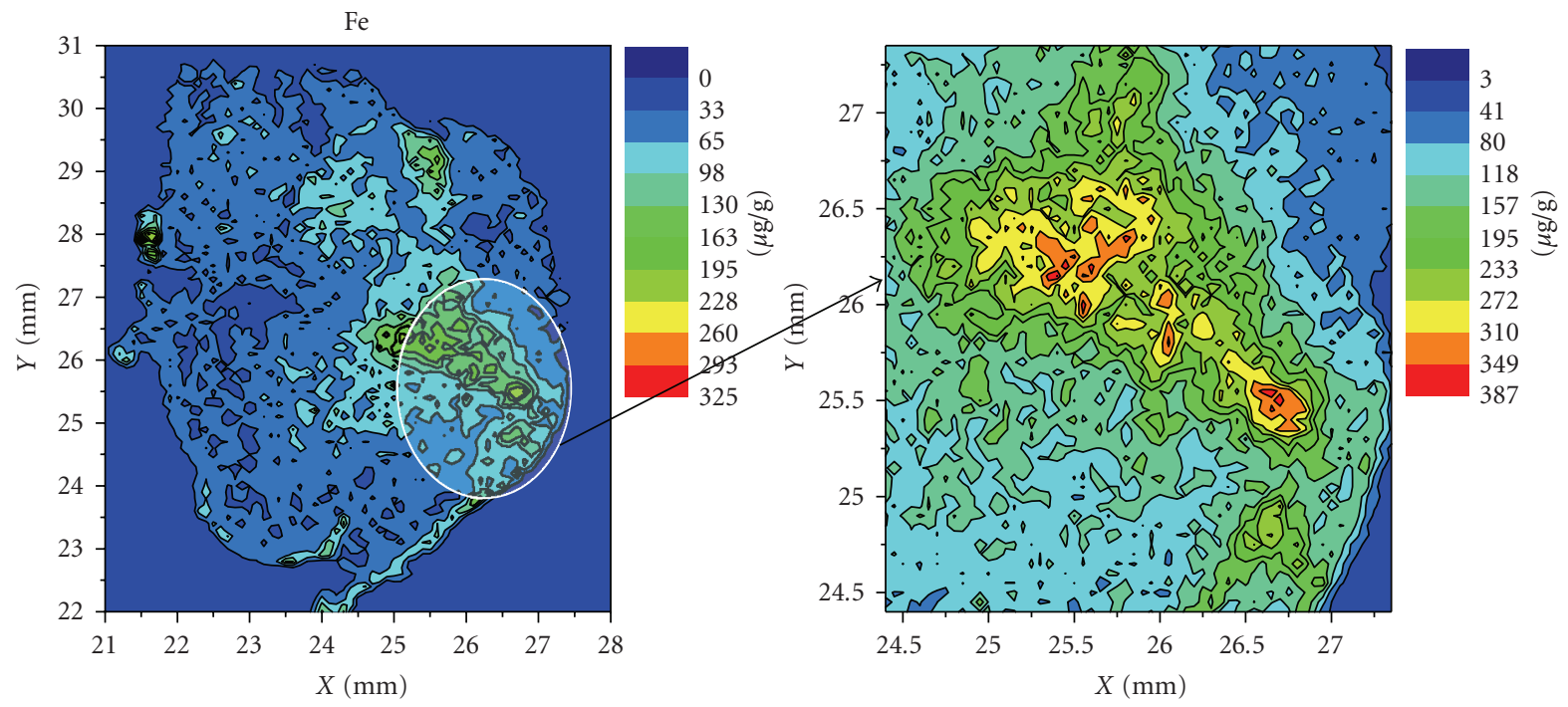

Figure 11: Raster scans of the Fe peak intensity for the APP mouse brain section. The entire section is shown on the left with 5 sec/0.1 mm step. An expanded region is shown on the right with $10 \mathrm{sec} / 0.05 \mathrm{~mm}$ step. Note that the number of counts per step has been converted to Fe concentration in $\mu \mathrm{g} / \mathrm{g}$ in this figure.

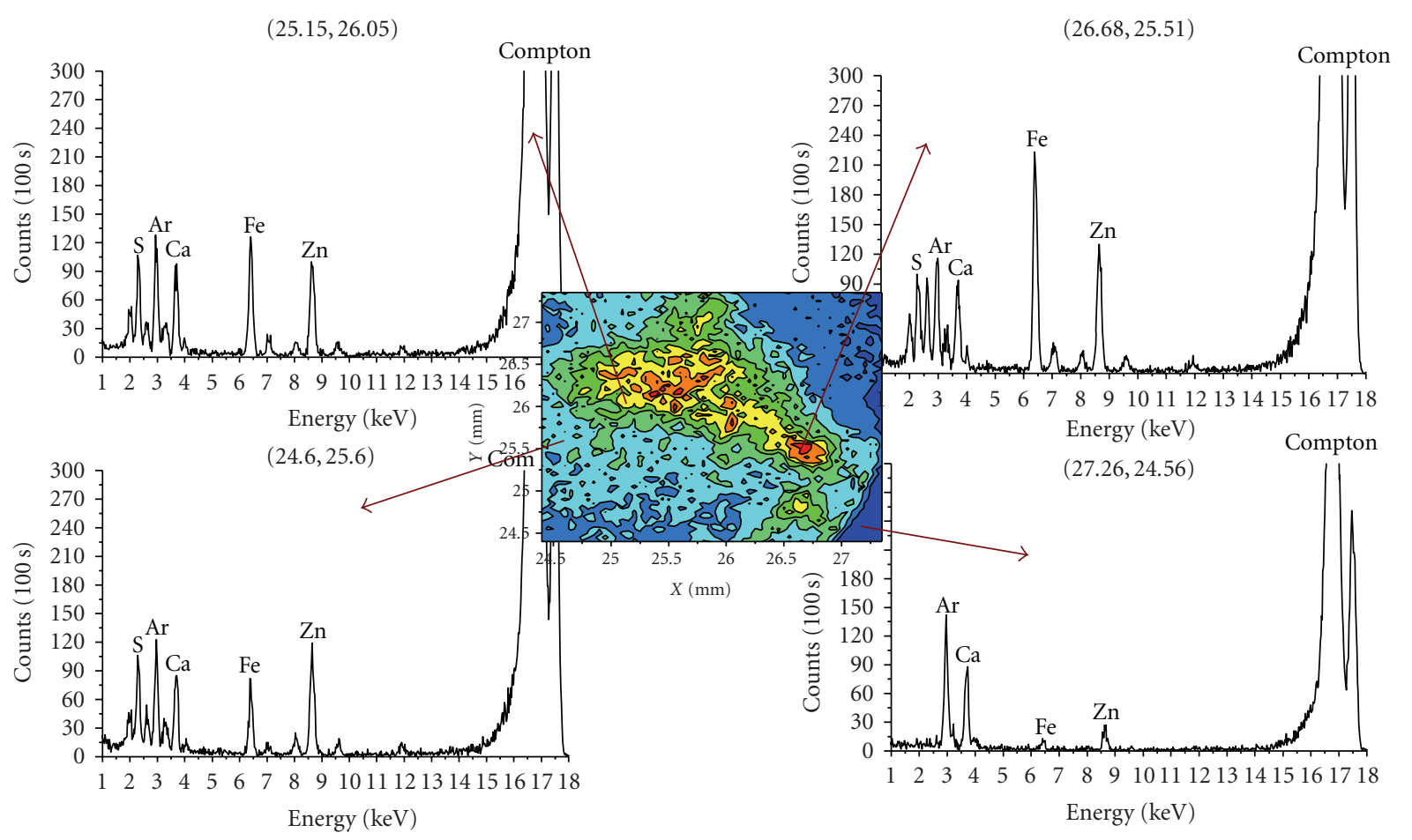

Figure 12: X-ray spectra for selected points on the Fe map of APP mouse brain section.

scanning of $2 \mathrm{~cm} \times 2 \mathrm{~cm}$ samples (in $\sim 2$ hours) and ultrahigh resolution of specific areas of interest.

\subsubsection{Measurements of Goat Tibia Bone Section}

In collaboration with Wadsworth Laboratory (New York State Department of Health), a series of measurements were carried out on a section of the tibia of a sacrificed goat that had been fed a diet containing lead [34]. These measurements are summarized in order to show application of the technique for a thick solid material and to allow the results to be compared to measurements carried out by a different technique, laser ablation, inductively coupled plasma mass spectroscopy (LA-ICP-MS).

Figures 15, 16, and 17 show the results of scanning of a $5 \mathrm{~mm}$ thick goat bone tibia section. 


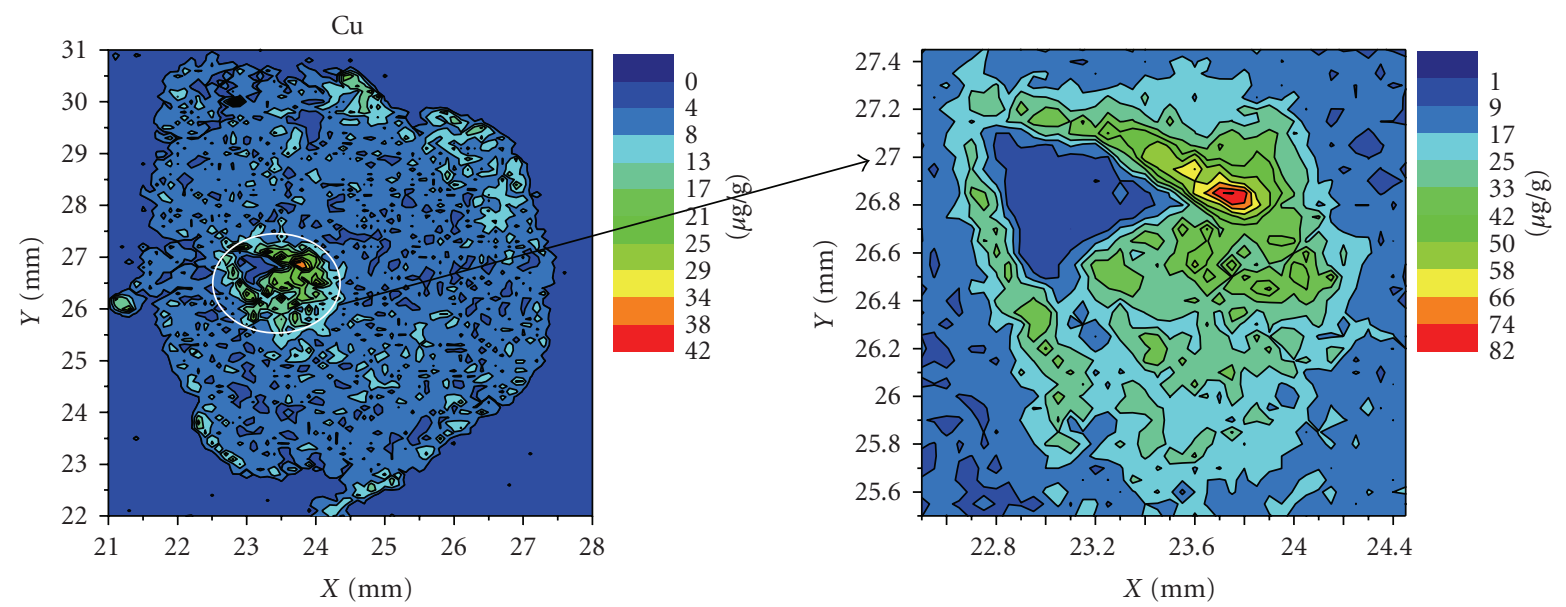

FIgURE 13: Raster scans of the Cu peak intensity for the APP mouse brain section.
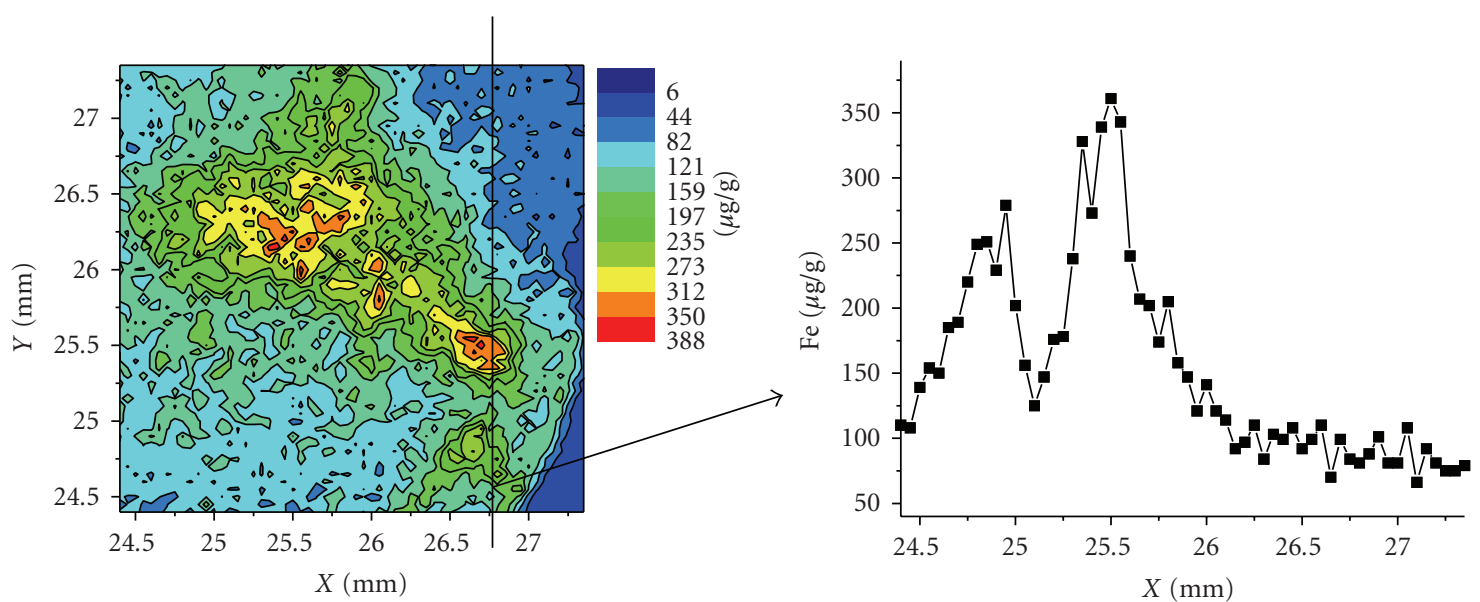

(a)
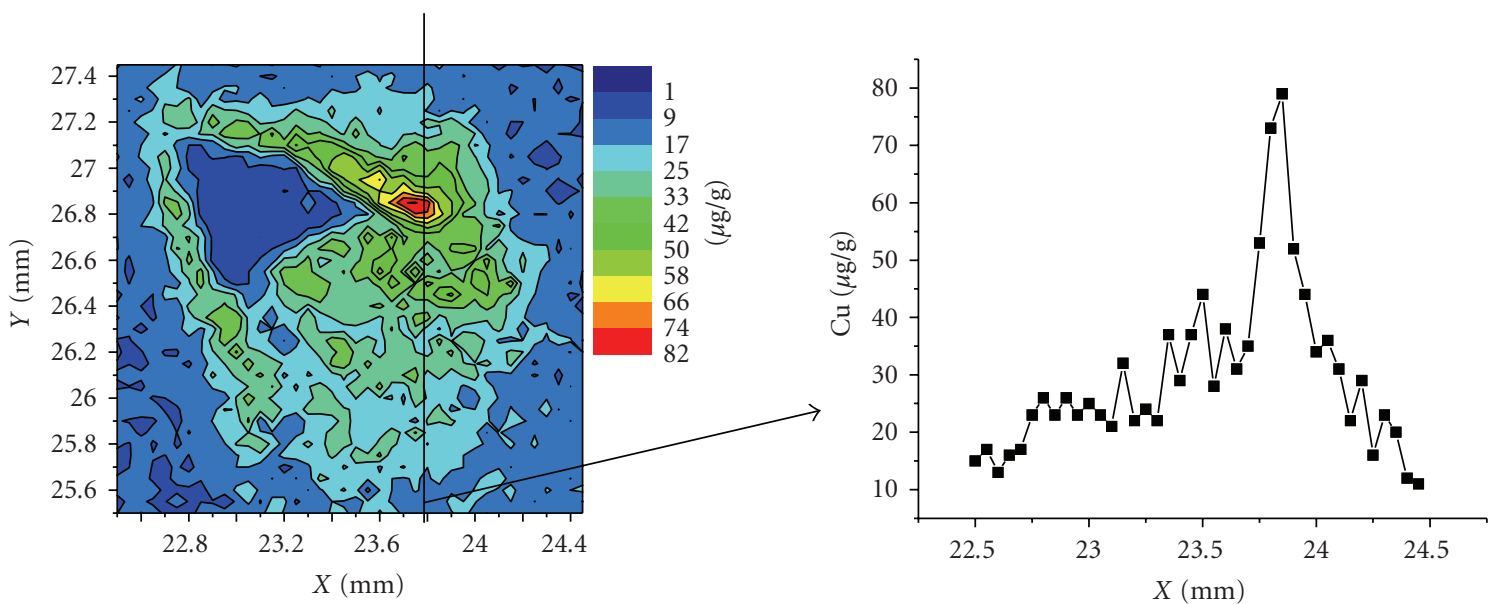

(b)

FIGURE 14: Quantitative scans of selected slices of Fe and $\mathrm{Cu}$ distributions of APP mouse brain scans. 


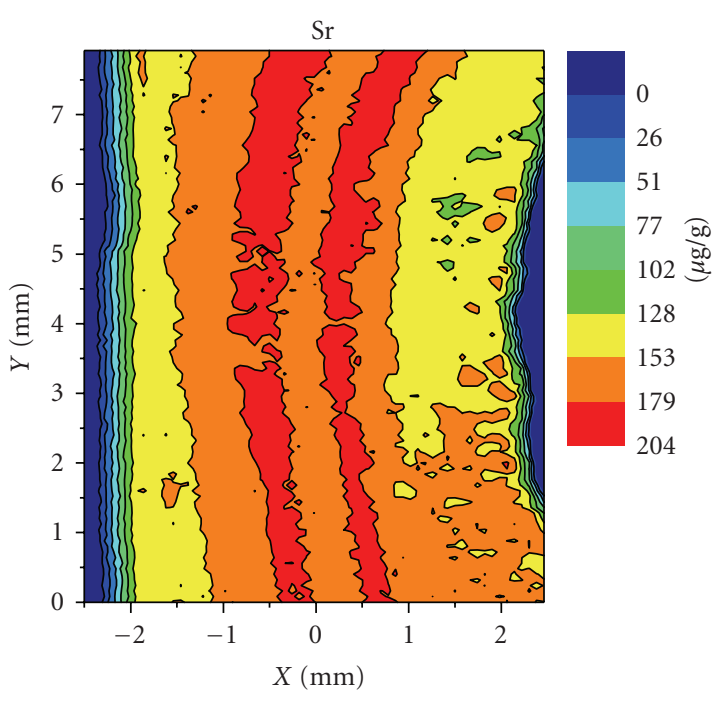

(a)

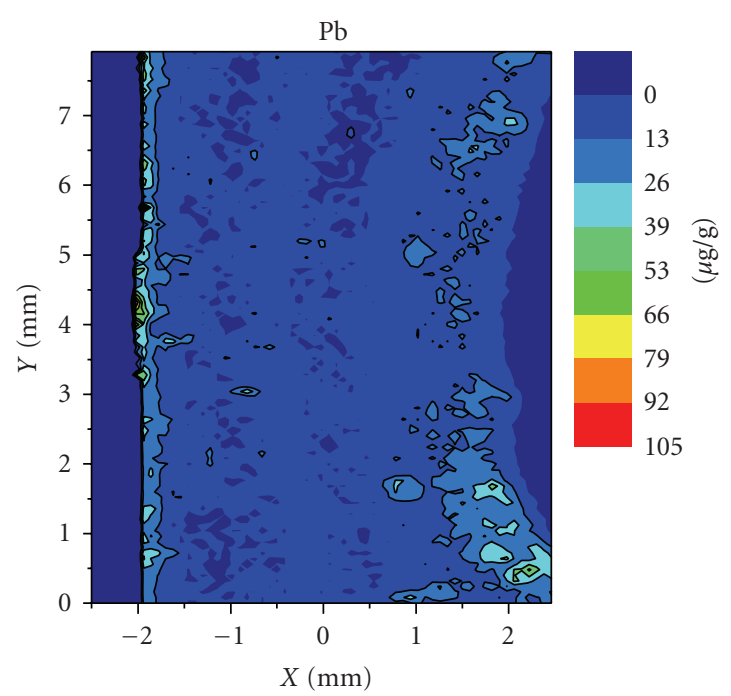

(c)

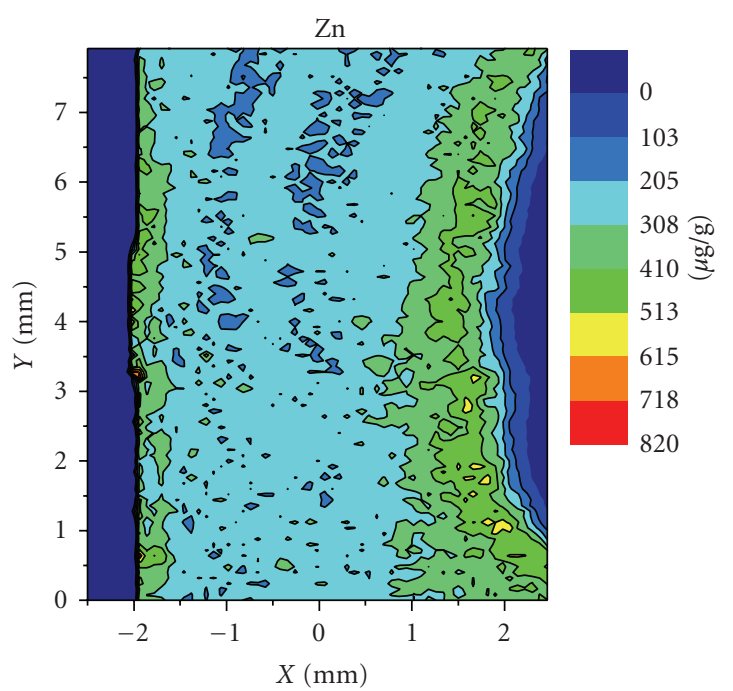

(b)

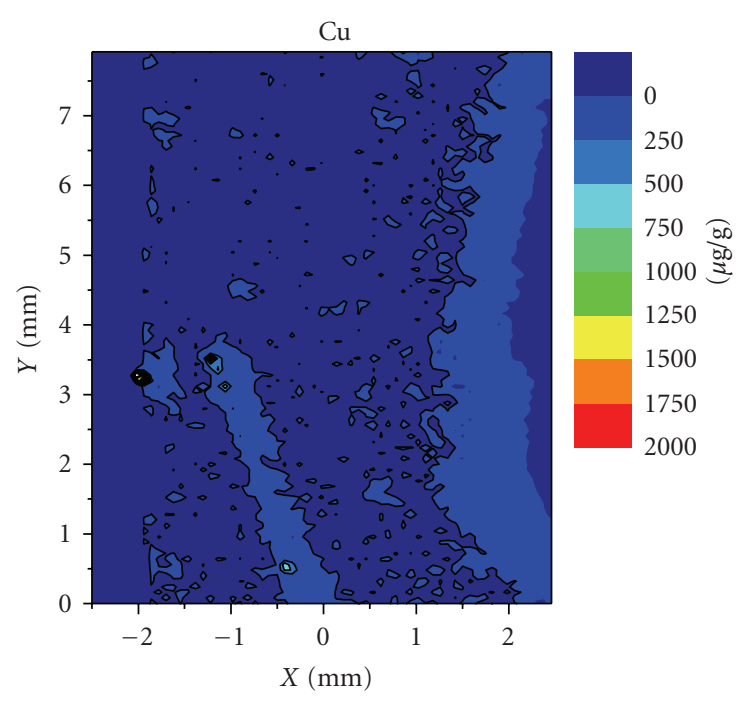

(d)

Figure 15: Elemental maps for the goat bone section.

These bone scans show a great deal of detail in the elemental distributions. They also show that it is possible to detect unexpected anomalies such as the interesting copper seam shown in Figure 15. They also show that it is possible to use the HD XRF scanning with different types of material and with thick samples. A comparison of the HD XRF scans with scans using LA-ICP-MS shown on Figure 18 gives good and even quantitative correlation. Indeed, the X-ray fluorescence results show more detail in the distributions and are more stable than the LA-ICP-MS technique. Furthermore, they are easier to do, faster, less expensive, and can be repeated, perhaps at higher resolution since they are nondestructive compared to the LA-ICP-MS method which erodes the sample.

\section{HD XRF as a Platform Technology}

The trend toward increasing global regulation of toxins presents an opportunity for HD XRF as a platform technology to address a number of currently important applications. HD XRF brings several advantages over previous toxin detection technologies with the combined ability to nondestructively detect very low levels, isolate small features, and give reliable results across a wide range of toxic elements as demonstrated in Sections 2 and 3. Conventional XRF analyzers and more standard analytical chemistry techniques do not possess the needed combination of reliable results and low cost per test needed in today's tightening regulatory environment. Areas that are in need of these attributes 


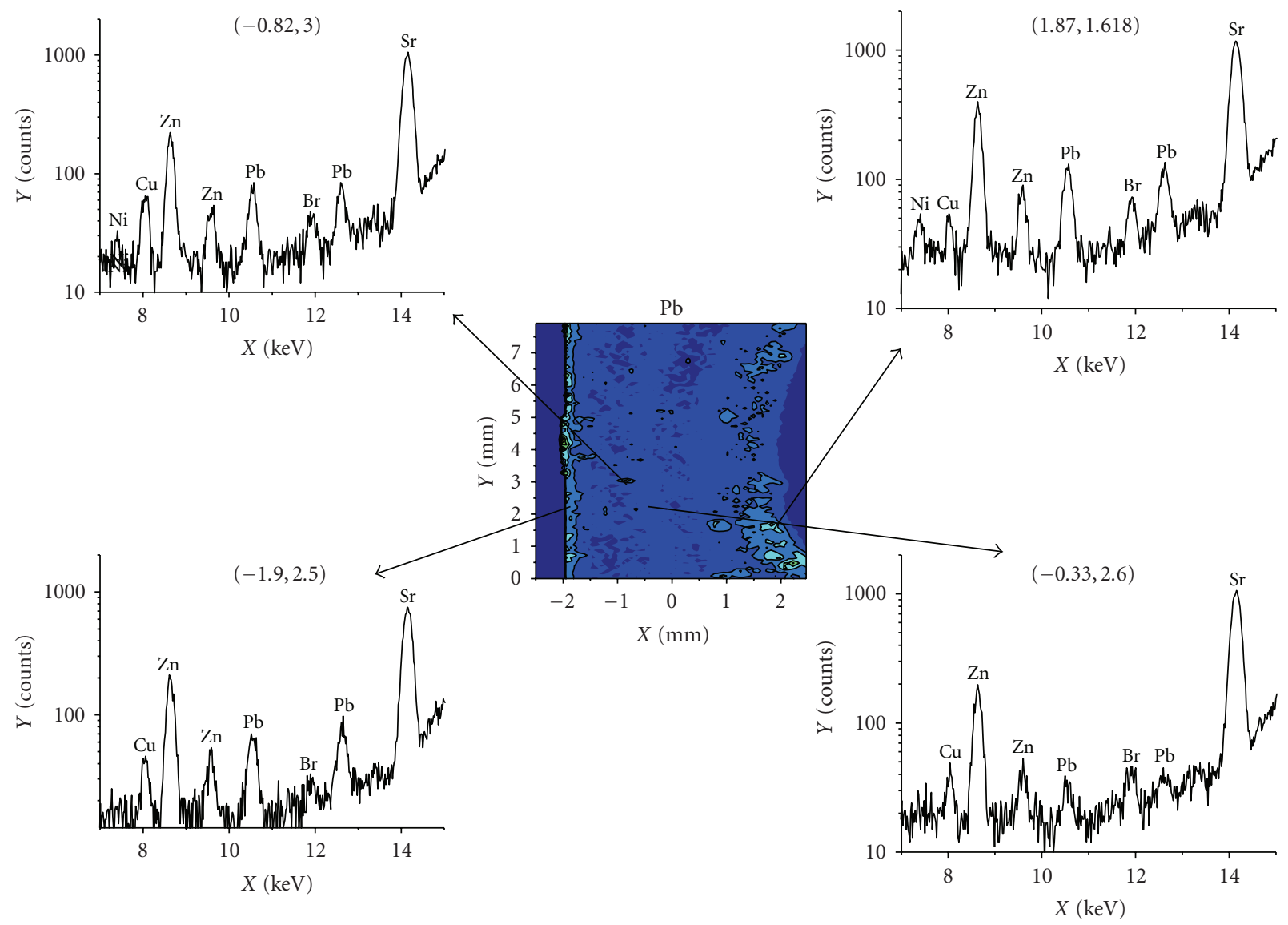

FIGURE 16: X-ray fluorescence spectra from selected positions on the bone section.

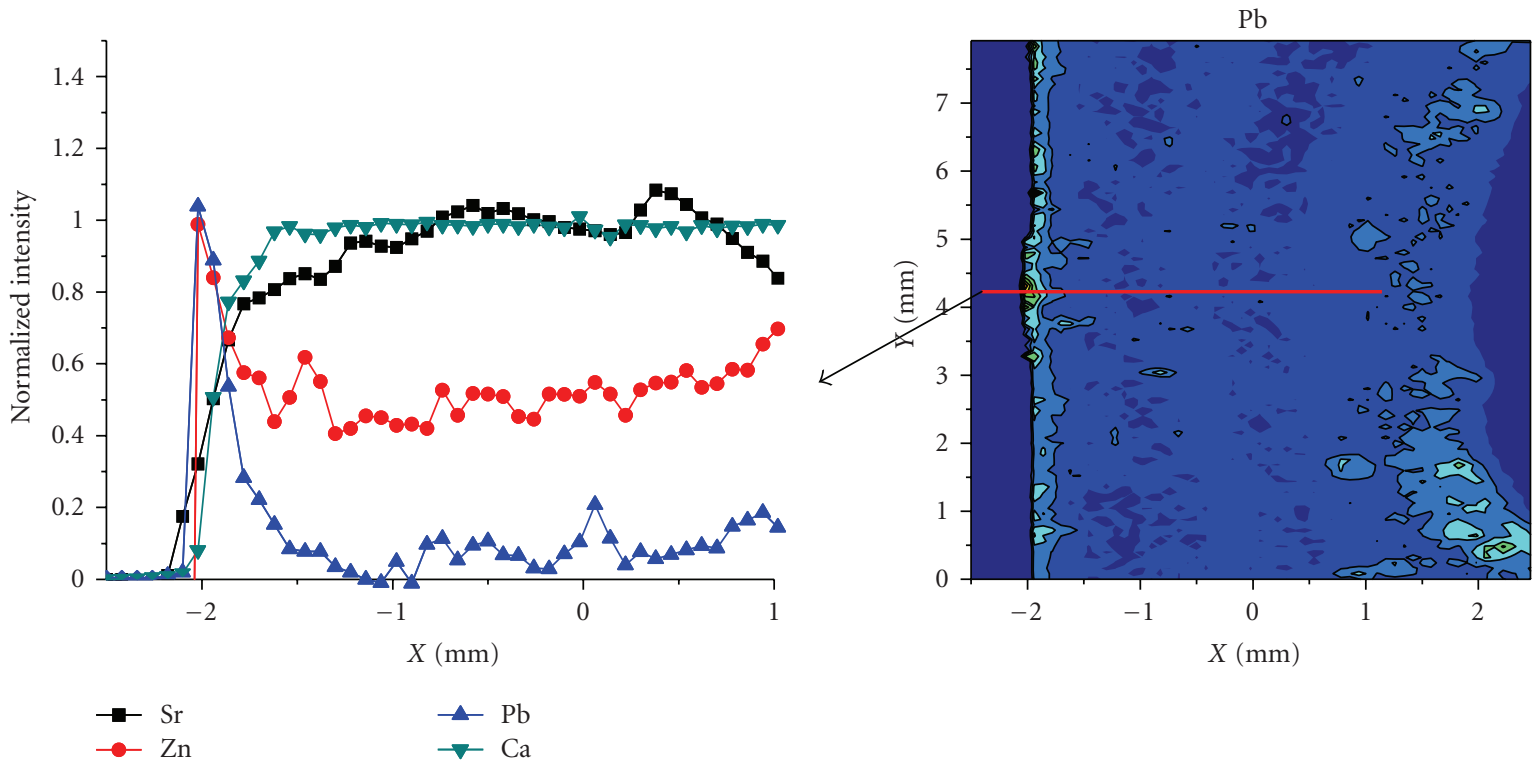

FIGURE 17: Elemental distributions along a selected path in the goat bone section. 


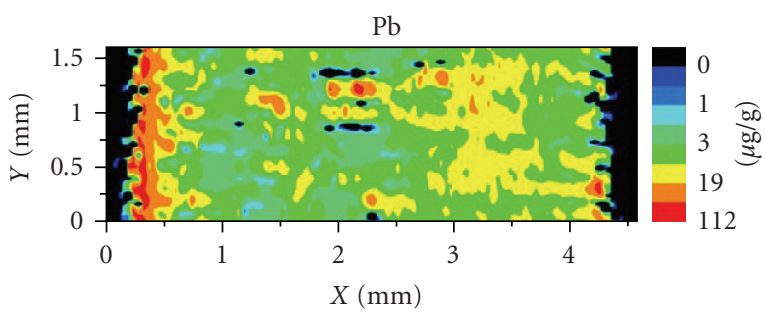

(a)

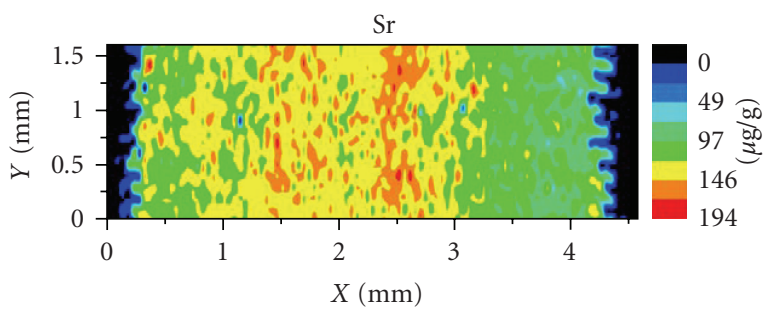

(b)

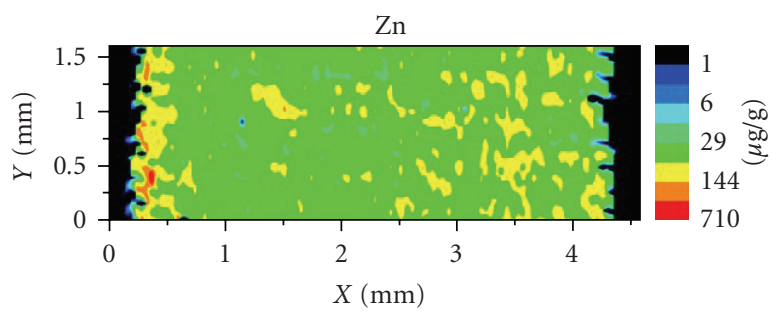

(c)

Figure 18: Laser ablation mass spectrometry-based elemental mapping of goat tibia bone crosssection [24].

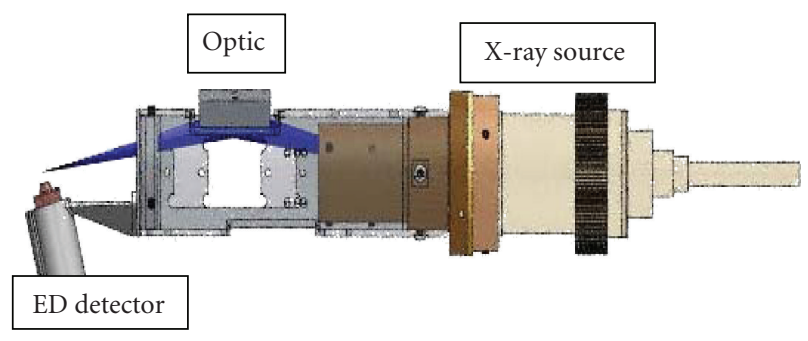

FIgURE 19: Schematic drawing of a portable HD-XRF analyzer measurement head.

include consumer products, electronics, air quality monitoring, body fluids, food products, and pharmaceuticals. Many of these applications can, in principle, share a common HD XRF hardware and software platform to hasten new product introductions and lower manufacturing costs

A prototype HD XRF analyzer has been developed. A schematic drawing of this prototype analyzer is shown in Figure 19.

\subsection{Lead in Toys}

As noted in Section 2.2.2, a topic of much current interest is the presence of lead in toys and other items to which children

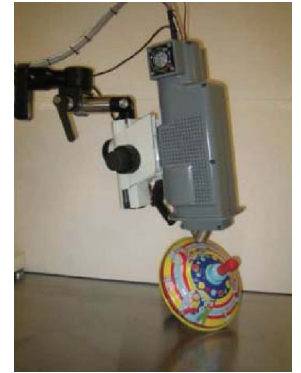

(a)

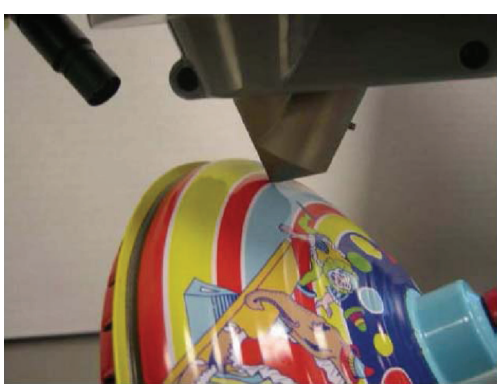

(b)
FIgure 20: Photograph of an HD XRF analyzer showing possible positioning boom.

are exposed. Infants and young children are particularly susceptible to lead poisoning. A nurturing child absorbs up to $50 \%$ more lead. Infants and young children have the tendency towards sucking on fingers and chewing on inedible products. Lead damages the central nervous system, causing delayed mental and physical development, attention, and learning deficiency. Any unnecessary exposure of children to lead should be avoided. The large number of toy recalls in the past two years and growing concern over continued existence of contaminated toys in use and in the distribution channel emphasize the need for a sensitive, quantitative, and efficient method for control of toxins in consumer products. The inefficiency and expense of current, largely chemical techniques available to measure contamination at the desired levels and with the necessary precision and accuracy have led to development of an easy-to-use HD XRF instrument for screening and quantitative evaluation of toys, jewelry, and other consumer products. Figure 20 shows photographs of such an analyzer currently under evaluation.

It is important to be able to measure small features as well as thin layers on toys. Examples of toys showing that lead is present in small features are shown in Figure 21. It is clear that the concern for lead in children's goods will soon extend to other toxic elements and to other consumer goods. The broad applicability of HD XRF for accurate and sensitive measurements of more than two dozen elements in virtually all materials and matrices make it a natural and powerful platform for such measurements.

\subsection{Toxins in Electronic Materials}

\section{RoHS}

Electronics manufacturing has also attracted significant regulatory control. RoHS (2002/96/EG) and WEEE (2002/95/EG) regulations have created the need to inspect electronics for global markets. This application is very attractive to HD XRF since the small spot capabilities for analysis of circuit board components of the type shown on Figure 22 offer a big advantage over handheld XRF and significant cost and time savings over bench top XRF and chemical digestion methods. The actual HD XRF instrument may be a stand-alone manually operated system 

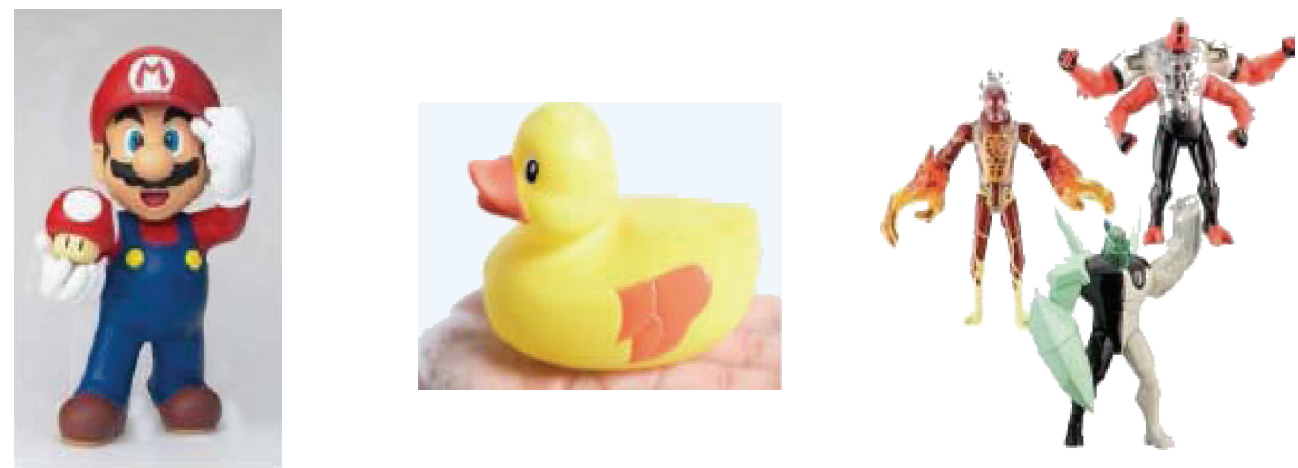

Figure 21: Examples of toys on which small features need to be tested for presence of toxic materials.

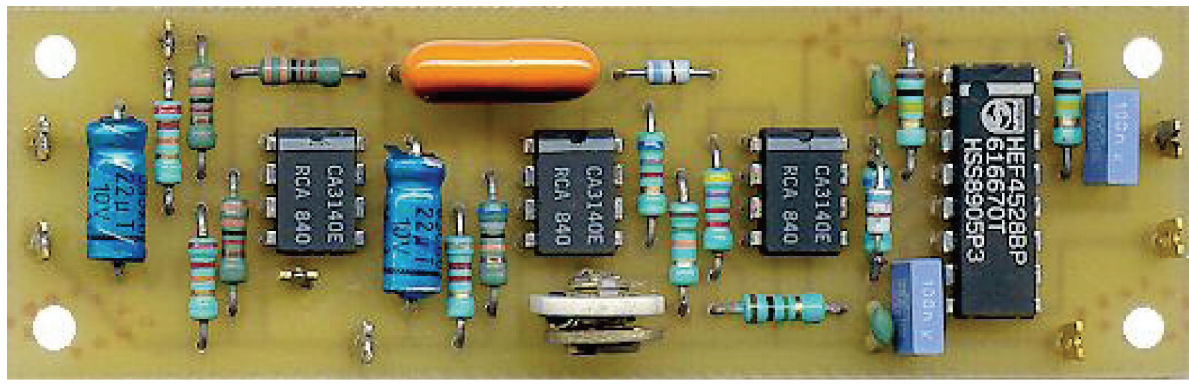

Figure 22: An example electronic circuit board showing small and tightly packed components that need to be separately evaluated for RoHS compliance.

similar to the HD XRF analyzer shown in Figure 20, or a programmable automated system integrated with other inspection technologies within a factory.

\section{Conclusions}

Selected examples show the usefulness of HD XRF in a wide range of applications in science, medicine, and industry. By judicious choice of the source, optics, and detector type, and configuration, it is possible to reach previously unattained levels of sensitivity (down to a few ppb), elemental specificity, and spatial definition in compact, low-power, reliable, rugged, and nondestructive analyzers for clinical-, field-, online-, and laboratory-based applications.

\section{Acknowledgments}

The work reported here has been supported in part by DOE DE-FG-02-99ER82918, DOE, DE-FG02-04ER84122; NIH 2R44RR021797-02; NIH 2R44RR22001-02; NSF,DMI0091570, EPA, EP-D-06-089' and NYSERDA, Agreement no.9392 PON944. The content is solely the responsibility of the authors and does not necessarily represent the official views of the Department of Energy, the National Institutes of Health, the National Science Foundation, the Environmental Protection Agency or the New York State Energy Development Authority. We gratefully acknowledge support and contributions from Dr. Earl Zimmerman, director of the Alzheimer's Center (Albany Medical Center, Albany, NY,
USA); Professor Rae Nishi (University of Vermont, Vt, USA), Dr. Patrick Parsons, and Dr. David Bellis (Wadsworth Center, New York State Department of Health, Albany, NY, USA). We are particularly appreciative of the help and support of many colleagues at X-Ray Optical Systems (East Greenbush, NY, USA) including Adam Bailey, Scott Semen, and Kai Xin.

\section{References}

[1] Z. W. Chen, W. M. Gibson, and H. Huang, "High definition X-ray fluorescence: principles and techniques," X-Ray Optics and Instrumentation, vol. 2008, Article ID 318171, 10 pages, 2008.

[2] J. Firket, "Fog along the Meuse Valle," Transactions of the Faraday Society, vol. 32, pp. 1191-1194, 1936.

[3] W. P. D. Logan, "Mortality in the London fog incident, 1952," The Lancet, vol. 261, no. 6755, pp. 336-338, 1953.

[4] A. Ciocco and D. J. Thompson, "A follow-up of Donora ten years after: methodology and findings," American Journal of Public Health and the Nation's Health, vol. 51, no. 2, pp. 155164, 1961.

[5] D. V. Bates, "Health indices of the adverse effects of air pollution: the question of coherence," Environmental Research, vol. 59, no. 2, pp. 336-349, 1992.

[6] R. Bascom, P. A. Bromberg, D. A. Costa, et al., "Health effects of outdoor air pollution," American Journal of Respiratory and Critical Care Medicine, vol. 153, no. 1, pp. 3-50, 1996.

[7] U.S. Environmental Protection Agency, "National Ambient Air Quality Standards for Particulate Matter," Federal Register, vol. 62, no. 138, pp. 38651-38760, 1997.

[8] CDC, report on human exposure, 2005. 
[9] Genes, Environment and Health Initiative (GEI), National Institutes of Health, Bethesda, Md, USA, http://www.gei.nih .gov/exposurebiology/index.asp.

[10] The National Children's Study, http://www.nationalchildrensstudy.gov/.

[11] Research Triangle Institute, North Carolina, private communication.

[12] P.J. Parsons, "Atomic spectroscopy in clinical chemistry," in Encyclopedia of Analytical Chemistry, R.A. Myers, Ed., pp. 1091-1123, John Wiley and Sons Ltd., Chichester, 2000.

[13] L.M. Sayre, G. Perry, C.S. Attwood, and M.A. Smith, "The role of metals in neurodegenative diseases," Cellular and Molecular Biology, vol. 46, no. 4, pp. 731-741, 2000.

[14] R.N. Rosenbeg, "The molecular and genetic basis of $\mathrm{AD}$ : the end of the beginning: the 2000 Warttenberg Lecture," Neurology, vol. 54, pp. 2045-2054, 2000.

[15] A. Ala, A.P. Walker, K. Ashkan, J.S. Dooley, and M.L. Schilsky, "Wilson's disease," Lancet, vol. 369, no. 9559, 2007.

[16] A. Pietrangelo, "Hereditary hemochromatosis-a new look at an old disease," New England Journal of Medicine, vol. 350, no. 23, pp. 2383-2397, 2004.

[17] B.P. Lanphear, R. Hornung, J. Khoury, et al., "Low-level environmental lead exposure and children's intellectual function: an international pooled analysis," Environmental Health Perspective, vol. 113, no. 7, pp. 894-899, 2005.

[18] W.R. Chappell Jr, C.O. Abernathy, R.I. Calderon, et al., "Arsenic Exposure and Health Effects," , Ed., Elsevier, Amsterdam, The Netherlands, 1999.

[19] J. Burger, A. Stern, and M. Gochfeld, Eds., "Mercury in commercial fiash: optimizing individual choices to reduce risk," Environmental Health Perspectives, vol. 113, no. 3, pp. 266-271, 2005.

[20] M.J. Schroder, "Cadmium," in Experimental and Clinical Neurotoxicology, P. S. Spencer and H.H. Schaumberg, Eds., pp. 276-280, 2nd Edition edition, 2000, Oxford University Press, NY, USA, 2000.

[21] P. S. Spencer and H.H. Schaumberg, Eds., "Experimental and Clinical Neurotoxicology," 2nd Edition edition, Oxford University Press, NY, USA, 2000.

[22] L. Goodman, "Alzheimer's disease - a clinicopathologic analysis of 23 cases with a theory on pathogenisis," The Journal of Nervous and Mental Disease, vol. 118, pp. 97-130, 1953.

[23] D. P. Perl and P. F. Good, "Comparative techniques for determining cellular iron distribution in brain tissues," Annals of Neurology, vol. 32, no. S1, pp. S76-S81, 2004.

[24] C. M. Morris, J. M. Candy, A. E. Oakley, C. A. Bloxham, and J. A. Edwardson, "Histochemical distribution of non-haem iron in the human brain," Acta Anatomica, vol. 144, no. 3, pp. 235257, 1992.

[25] L. M. Sayre, G. Perry, P. L. R. Harris, Y. Liu, K. A. Schubert, and M. A. Smith, "In situ oxidative catalysis by neurofibrillary tangles and senile plaques in Alzheimer's disease: a central role for bound transition metals," Journal of Neurochemistry, vol. 74, no. 1, pp. 270-279, 2000.

[26] J. F. Schenck and E. A. Zimmerman, "High-field magnetic resonance imaging of brain iron: birth of a biomarker?" NMR in Biomedicine, vol. 17, no. 7, pp. 433-445, 2004.

[27] E. M. Haacke, N. Y. C. Cheng, M. J. House, et al., "Imaging iron stores in the brain using magnetic resonance imaging," Magnetic Resonance Imaging, vol. 23, no. 1, pp. 1-25, 2005.
[28] L. M. Miller, Q. Wang, T. P. Telivala, R. J. Smith, A. Lanzirotti, and J. Miklossy, "Synchrotron-based infrared and $\mathrm{X}$-ray imaging shows focalized accumulation of $\mathrm{Cu}$ and $\mathrm{Zn}$ co-localized with $\beta$-amyloid deposits in Alzheimer's disease," Journal of Structural Biology, vol. 155, no. 1, pp. 30-37, 2006.

[29] A. Mikhaylova, M. Davidson, H. Toastmann, et al., "Detection, identification and mapping of iron anomalies in brain tissue using X-ray absorption spectroscopy," Journal of the Royal Society Interface, vol. 2, no. 2, pp. 33-37, 2005.

[30] J. F. Collingwood, A. Mikhaylova, M. Davidson, et al., "In situ characterization and mapping of iron compounds in Alzheimer's disease tissue," Journal of Alzheimer's Disease, vol. 7, no. 4, pp. 267-272, 2005.

[31] J. F. Collingwood, A. Mikhaylova, M. R. Daavidson, et al., "High-resolution X-ray absorption spectroscopy studies of metal compounds in neurodegenerative brain tissue," Journal of Physics: Conference Series, vol. 17, pp. 54-60, 2005.

[32] J. Collingwood and J. Dobson, "Mapping and characterization of iron compounds in Alzheimer's tissue," Journal of Alzheimer's Disease, vol. 10, no. 2-3, pp. 215-222, 2006.

[33] A. Ide-Ektessabi, T. Kawakami, and F. Watt, "Distribution and chemical state analysis of iron in the Parkinsonian substantia nigra using synchrotron radiation micro beams," Nuclear Instruments and Methods in Physics Research Section B, vol. 213, pp. 590-594, 2004.

[34] D. J. Bellis, Z. Chen, W. M. Gibson, and P. J. Parsons, "Element distribution in bone measured by focused monochromatic microbeam X-ray fluorescence with a low-power source coupled to doubly curved crystal optics," submitted to Journal of Analytical Atomic Spectrometry. 